\title{
DOES THE TRIHYDRATE OF ATORVASTATIN CALCIUM POSSESS A MELTING POINT?
}

Chaima Tizaoui, ${ }^{1,2,3}$ Haykel Galai, ${ }^{2}$ Maria Barrio, ${ }^{4}$ Simon Clevers, ${ }^{1}$ Nicolas Couvrat, ${ }^{1}$ Valérie Dupray, ${ }^{1}$ Gérard Coquerel, ${ }^{1}$ Josep-Lluis Tamarit, ${ }^{4}$ Ivo B. Rietveld ${ }^{1,5, *}$

\footnotetext{
${ }^{1}$ SMS laboratory (EA 3233), Université de Rouen-Normandie, Place Émile Blondel, 76821 Mont Saint Aignan, France

${ }^{2}$ Laboratory of Materials, Treatment and Analysis (LMTA), National Institute of Research and Physical-chemical Analysis, Technopark of Sidi-Thabet, 2020 Ariana, Tunisia.

${ }^{3}$ Faculté des Sciences de Bizerte, Université de Carthage, 7021 Zarzouna Bizerte, Tunisia.

${ }^{4}$ Grup de Caracterització de Materials, Departament de Física and Barcelona Research Center in Multiscale Science and Engineering, Universitat Politècnica de Catalunya, EEBE, Campus Diagonal-Besòs, Av. Eduard Maristany 10-14, E-08019 Barcelona, Catalonia, Spain.
}

5 Faculté de Pharmacie, Université de Paris, 4 avenue de l’observatoire, 75006 Paris, France.

* Corresponding author: ivo.rietveld@univ-rouen.fr

\begin{abstract}
To decide whether an active pharmaceutical ingredient can be used in its amorphous form in drug formulations, often the glass transition is studied in relation to the melting point of the pharmaceutical. If the glass transition temperature is high enough and found relatively close to the melting point, the pharmaceutical is considered to be a good glass former. However, it is obviously important that the observed melting point and glass transition involve exactly the same system, otherwise the two temperatures cannot be compared. Although this may seem trivial, in the case of hydrates, where water may leave the system on heating, the composition of the system may not be evident. Atorvastatin calcium is a case in point, where confusing terminology, absence of a proper anhydrate form, and loss of water on heating lead to several doubtful conclusions in the literature. However, considering that no anhydrate crystal has ever been observed and that the glass transition of the anhydrous system is found at $144{ }^{\circ} \mathrm{C}$, it can be concluded that if the system is kept isolated from water, the chances that atorvastatin calcium crystallises at room temperature is negligible. The paper discusses the various thermal effects of atorvastatin calcium on heating and proposes a tentative binary phase diagram with water.
\end{abstract}

Keywords: active pharmaceutical ingredient, thermal properties, glass transition, binary phase diagram, hydrate, kinetic stability 
Reviewers' comments:

We thank the reviewers for their thorough review of our paper. We will respond to their individual remarks below.

Reviewer \#1: The paper is devoted to studying dehydration process of atorvastatin calcium trihydrate by TG, DSC, X-ray diffraction at different temperature, hot-stage microscopy, TR-SHG. The results have been interpreted using phase-diagram method. The presented work is interesting with point of view understanding mechanism(s) of phase transition(s) at dehydration and melting processes. This paper is oriented on the special auditorium connected with detailed analysis of possible mechanism of the phase transition(s). The discussions/interpretations of the experimental data are speculative and oriented on the special Journal(s), for example, Journal of Thermal Analysis and Calorimetry or Themochimica Acta.

Response:

We understand the concerns of the reviewer that the paper is oriented towards phase behaviour. However, it is exactly for this reason why we wish to publish our findings of a blockbuster drug compound in a pharmaceutical journal. If one studies the literature on the thermal behaviour of this compound in the pharmaceutical literature, a lot of the interpretation is not correct (see the introduction of our paper), whereas understanding the solid state of a drug compound is of major importance in drug development, quality control, and patenting. We hope that this contribution will improve the understanding of the solidstate behaviour of atorvastatin calcium in particular and in a more general sense in the pharmaceutical community. Moreover, the conclusion of the paper, that amorphous atorvastatin will remain amorphous in the absence of water has not been mentioned in the literature before and is clearly of interest for the formulation of this drug molecule. We have difficulties placing the remark that the discussion and interpretation of the experimental data is speculative. Most of the conclusions are supported by multiple experimental methods and data. The only speculation that we are aware of is the conclusion that the binary phase diagram of atorvastatin calcium and water contains a peritectic melting transition and not a congruent melting transition. We have added a new Figure S5, which demonstrates the melting behaviour of the trihydrate of atorvastatin calcium under open and closed conditions. For the latter condition, two domains in the melted sample can be observed, which suggest that the melting is indeed incongruent.

Reviewer \#3: The authors have performed a detailed study on a system that has already been studied extensively, atorvastatin calcium trihydrate. In this case, the question is whether there is enough new information to justify publication. What is known already include the phase transitions (notably studied by Christensen et al.), multiple DSC and TGA studies, and an approximate phase diagram. What this manuscript adds includes a much better understanding of the phase transitions occurring near $150 \mathrm{C}$, confirmation of the "residual" crystallinity (however that is defined) that exists after heating to 150 C by SHG and PXRD, and a closed pan DSC study showing that the trihydrate apparently melts around $160 \mathrm{C}$. 
Much of the discussion is a summary of what is provided in the literature, coupled with the experimental data. I am not sure that I like the title of the discussion about the glass transition and melting temperature being only five to ten degrees apart, as this is misleading, in the basic sense that it is comparing the anhydrous form of atorvastatin for the glass transition temperature to the trihydrate form (as the authors note), where if there were indeed three molecules of water for every atorvastatin molecule, the $\mathrm{Tg}$ would be substantially lower (although still not $2 / 3$ ) (which the authors should discuss). On balance, it is a good addition to the literature, although the amount of new data is relatively small.

Response:

We have changed the title of section 4.2, which was a direct reference to the text in the introduction to "The glass transition at $144^{\circ} \mathrm{C}$ in relation to the observed thermal events in the atorvastatin calcium hydrate system".

We disagree that we only summarize the literature in which the thermal behavior is often not properly interpreted and in which water loss peaks are interpreted as melting of the compound. Moreover, certain authors conclude that atorvastatin is a good glass former because the $\mathrm{Tg}$ is very close to the melting point (see introduction of our paper and the references). One of the objectives of the paper is to highlight that the conclusion of atorvastatin being a good glass former results from a confusion between two different systems as the reviewer mentions just above and which as he indicates we have mentioned in our text. The paper that provides the most useful information is certainly that of Christensen et al., but this may escape the scientists that base themselves mainly on DSC and X-ray diffraction as papers published after Christensen still contain incorrect interpretations. Nonetheless, judging from the variation in comments from the different reviewers, atorvastatin calcium is not an easy system to understand. We really hope that our revision does contribute to this understanding which is one of the reasons that we wrote this paper.

As for the Tg in the presence of water, we have considered looking at this, however, the presence of water triggers crystallization. In addition, it will be really hard to keep the concentration of water constant at higher temperatures and therefore any $\mathrm{Tg}$ that we will measure cannot be easily linked to the system. Considering that we are dealing in this case with a mixture of a small solvent molecule and a salt, we are definitely not sure whether the $2 / 3$ rule is still applicable, also because the "melting" temperature of the system is in fact a peritectic and not a proper melting point as defined for a congruently melting co-crystal or a pure compound.

On the other hand, why is the reviewer so sure that the glass transition won't be found at about $2 / 3$ of the melting point? The glass transition of pure water is found at $136 \mathrm{~K}$ (Swenson and Teixeira, 2010), thus as a very rough estimate one would expect the glass transition temperature of a $50 / 50 \%$ mixture to be around $(144+273+136) / 2=276 \mathrm{~K}$, which is close to $2 / 3$ of $428 \mathrm{~K}$ (the peritectic of the trihydrate). But we have to admit, that we do not know how to measure this reliably taking in consideration mixing problems, possible crystallization of the system, and vaporization of water. We are not sure therefore what to do with the remark of the reviewer between parentheses that we should discuss the $\mathrm{Tg}$ of the mixed system. 
- $\quad$ Section 3.2 - While it is reasonable to discuss the events of the DSC/TGA with respect to the structure, I would add a ", which most likely explains the high temperature at which...". This is also consistent with the next sentence in the paragraph.

Response: we have added 'most likely' to the sentence

Section 3.3 - it seems strange to change from endo down to endo up

Response: we have changed the DSC/TGA figure 4 in section 3.2 into endo up

Section 3.4 - could transition be due to polymorphic change or melting of a small amount of crystalline material? This should at least be mentioned in this section, even though it is explored later in the manuscript

Response: polymorphic change is excluded, because heating past the small peak and cooling results in the observation of a glass transition, which indicates that the sample has become liquid. It is therefore indeed a kind of melting (see also Figure S3 in the supplementary materials). We have added the following phrase in this section:

"it may represent a kind of melting transition, because after its occurrence on cooling a glass transition is observed."

- $\quad$ Section 4.1 - I dislike this title, as it really refers to what happens to atorvastatin calcium trihydrate as a function of water activity

Response: We have changed the title into: "How could the observed calorimetric behaviour be interpreted". Although the reviewer is right that the observed behaviour is the result of the water activity, this water activity is hard to quantify, (unless we manage to determine the water vapor pressure of the hydrate around $150^{\circ} \mathrm{C}$, which will not be easy with the equipment that we have available in the laboratory), but we would like to avoid the phrase "as a function of water activity", because it may appear that we have precise knowledge of this quantity.

- $\quad$ Section 4.2 - I really dislike the title as it is misleading

Response: We have changed the title of section 4.2 , which was a direct reference to the text in the introduction to "The glass transition at $144^{\circ} \mathrm{C}$ in relation to the observed thermal events in the atorvastatin calcium hydrate system".

Reviewer \#4: Review of the manuscript, entitled: "Does the Trihydrate of Atorvastatin Calcium Possess a Melting Point?", submitted by Tizaoui et al. to European Journal Pharmaceutical Sciences.

In the submitted manuscript Tizaoui et al applied a wide array of experimental methods to understand what is happening upon heating of atorvastatin calcium trihydrate and propose a phase diagram of its binary mixture with water. The other important issue they 
Touched is explanation of the thremograms of this compounds that seem to be very complex and far from being understood. I must admit that number of experimental data and analysis impressed me. Authors tried to do everything to find out what is going with the sample, how does dehydration proceeds, where is temperature of degradation of this important pharmaceutical ingredient (API). In this context it is worth to stress that in the literature there are plenty of data, very often contradictory, related to this topic. In the submitted paper Authors tried to sort it out the current state of the art with their new results. Interestingly in many aspects they found agreement and formulated similar conclusions to those reported by Christensen et al Pharm Res (2013). So in this context, except of constructing by the Authors binary phase diagram, any new insight has been reached Anyway since the problem of water, dehydration and systematic evolution of the properties of API due to this process is quite important for the Scientists dealing with solid forms of API this paper can be considered for publication in European Journal of Pharmaceutical Sciences.

Below is a list of my main concerns:

1) My main concern is related to the endothermic process observed around $144 \mathrm{C}$ in the collected thermograms. In fact Authors adopted interpretation of Christensen et al that at this temperature API forms mesophase. However no evidence to support this thesis was presented which would be additional value of this paper. To solve this problem one may try to extract order parameter from $X$ ray powder diffraction data, perform birefringence investigations. Moreover upon polarized microscopy investigations some texturing should be observed Second, is it possible that due to some balance between water and API (specific concentration of water to API) this system can be classified as some kind of lyotropic liquid crystal?

Response:

A glass transition at $144^{\circ} \mathrm{C}$ is observed in the case of an anhydrous vitreous system, whereas an endothermic peak is observed around $150^{\circ} \mathrm{C}$ in the case of heating the trihydrate resulting in a loss of water, which under $1 \mathrm{~K} / \mathrm{min}$ conditions (optical microscope) is completed at around $140^{\circ} \mathrm{C}$.

Cooling after passing the peak at $150^{\circ} \mathrm{C}$ leads to a glass transition (see Figure S3), indicating that a vitreous state appears, however, in case of cooling down before the $150^{\circ} \mathrm{C}$ peak has been passed no glass transition is observed indicating a presence of some sort of structure in the system. This is corroborated in particular by the SHG signal (Figure 9), which demonstrates a weak signal, which is proof of structure in the sample, without which no SHG signal would exist. In addition, the X-ray diffraction results in Figure 10 (up to $157^{\circ} \mathrm{C}$ ) indicate the presence of structuration in the sample, because of the small peak at $16^{\circ}$ 2theta. This behaviour classifies as a mesophase in between the solid phase and complete destruction of the existing solid structure above $150^{\circ} \mathrm{C}$ as it falls properly within the definition of a mesophase as mentioned in the book on liquid crystals "The physics of liquid crystals" by P.G. de Gennes and J. Prost (de Gennes and Prost, 1993), where the mesophase is described as an intermediate between the crystal and the isotropic liquid. We have added a phrase defining a mesophase and the reference to the book by de Gennes and Prost (de Gennes and Prost, 1993). 
To our knowledge it is not possible to obtain the order parameter from powder diffraction data as the angle theta in the determination of the order parameter is in fact perpendicular to the 2theta provided in the powder diffraction pattern. Therefore, the necessary data is not contained in the powder diffraction pattern.

It is hard to believe that a lyotropic liquid crystal will form with a mixture of water and API at $145^{\circ} \mathrm{C}$ in an open system, where the water can freely evaporate. The TGA/DSC measurements clearly indicate that at $140^{\circ} \mathrm{C}$ before the small peak is reached, which appears to be linked to the destruction of the mesophase, all weight loss has ceased and the system does not contain any water anymore. The small peak itself is not at all linked to a weight loss event (liberation of water). Thus, this suggestion is highly unlikely and the mesophase will most likely consist of a structured system that is a left-over of the trihydrate structure without the water molecules.

2) Fact that glass transition of the hydrated and purely anhydrous API must be much different is quite obvious and once we find very small gap between melting and glass transition temperature (as reported herein) it must be due to dehydration process. Authors presented this conclusion as something that is novel or new but it is not.

Response: We agree with the reviewer that this is not new and it is not our intention to make it sound new or novel. However, in several references on atorvastatin, the closeness is interpreted as being the hallmark of a good glass former, which in this reference (Shete et al., 2010) can be even seen mentioned in the abstract! This is one of the reasons that we present a binary phase diagram and that we discuss this point to make clear that in this case the melting and the glass transition have nothing to do with each other.

3) Did Authors try to run Temperature Modulated DSC measurements which allow to discriminate between reversible and non-reversible processes observed upon heating and cooling sample? These kind of investigations could be valuable.

Response: It is true that modulated DSC could have provided more information on the system. However, (1) the combination of the TGA/DSC measurements coupled to MS clearly shows water loss, which would be a non-reversible signal, because the water would have evaporated. (2) the small peak indicating the destruction of the mesophase is not reversible either as demonstrated by the measurements going down in temperature registering a glass transition and indicating a fully amorphous system, reheating the system also does not result in a reoccurrence of the small mesophase peak, so it is obviously not reversible. (3) the destruction of the system in a closed capsule would involve loss of water as it will be more than 50 degrees above its boiling point. The reinsertion of water will likely not be instantaneous, because the water will at this temperature be highly mobile. Even by cooling down the sample recrystallisation is also observed to be slow, thus this peak will most likely register as non-reversible.

4) Quite interesting finding is related to the physical stability of purely anhydrous atorvastatin calcium. It seems that warranting moisture free conditions may be alternative way to stabilize amorphous forms of API for which no anhydrous crystals are reported. Since atorvastatin calcium does not form anhydrous crystals one can try to see 


\section{whether this hypothesis is satisfied. May be in that way it could be possible to obtain new polymorphs of API of lower content of water that was not discovered so far?}

Response: it is our opinion that this is a rather solid observation. No recrystallisation in the absence of water. We would not be surprised if the original formulation is based on this in fact, because with a $\mathrm{Tg}$ at $144^{\circ} \mathrm{C}$ it becomes obvious that mobility at room temperature is negligible. Research is still ongoing on this point.

\section{5) Finally, Authors did not convince me that Trihydrate of Atorvastatin Calcium has a Melting Point.}

Response: We can see the point of the reviewer and we agree with him to the level that a peak in a DSC measurement is just that, a calorimetric response with a given enthalpy and at a given temperature. However, the remark of the reviewer can be turned around: what else?

(1) The capsule is closed and no weight loss has been registered after the measurement, indicating that the water vapor within the capsule will have been set by the (water) vapor pressure of the trihydrate. This implies that sudden loss of water by evaporation cannot happen, because the system follows the Clausius-Clapeyron curve in the P-T phase diagram. In addition, the return to the baseline after the main peak clearly indicates that the capsule does not leak, which would involve considerable heat effects.

(2) We observe a large peak with an enthalpy in the order of $130 \mathrm{~J} \mathrm{~g}^{-1}$. This enthalpic value excludes simple polymorphic transitions, which have values in the order of 10 $\mathrm{J} \cdot \mathrm{g}^{-1}$ or even lower.

(3) Opening the capsule after the measurement shows a glassy substance indicative of molten and resolidified sample.

(4) No significant decomposition has been observed, which tends to start above $180^{\circ} \mathrm{C}$.

Thus, a large peak leading to a liquid appearance in the cooled-down product as argued in section 3.6, without weight loss during the measurement (we have added this remark to section 3.6) and little or no decomposition; we see no other explanation than a congruent or incongruent melting point, which taking all observations together is most likely incongruent.

\section{References:}

de Gennes, P.G., Prost, J., 1993. The physics of liquid crystals. Clarendon Press, Oxford, UK. Shete, G., Puri, V., Kumar, L., Bansal, A.K., 2010. Solid state characterization of commercial crystalline and amorphous atorvastatin calcium samples. AAPS PharmSciTech 11, 598-609. Swenson, J., Teixeira, J., 2010. The glass transition and relaxation behavior of bulk water and a possible relation to confined water. J Chem Phys 132, 014508. 
Highlights

- Atorvastatin calcium is a very good glass former with a $\mathrm{Tg}$ at $144^{\circ} \mathrm{C}$

- Conversion conditions of the trihydrate to amorphous anhydrate are presented

- Inconsistencies between the melting point and the glass transition are clarified

- A tentative binary phase diagram with atorvastatin calcium and water is provided 


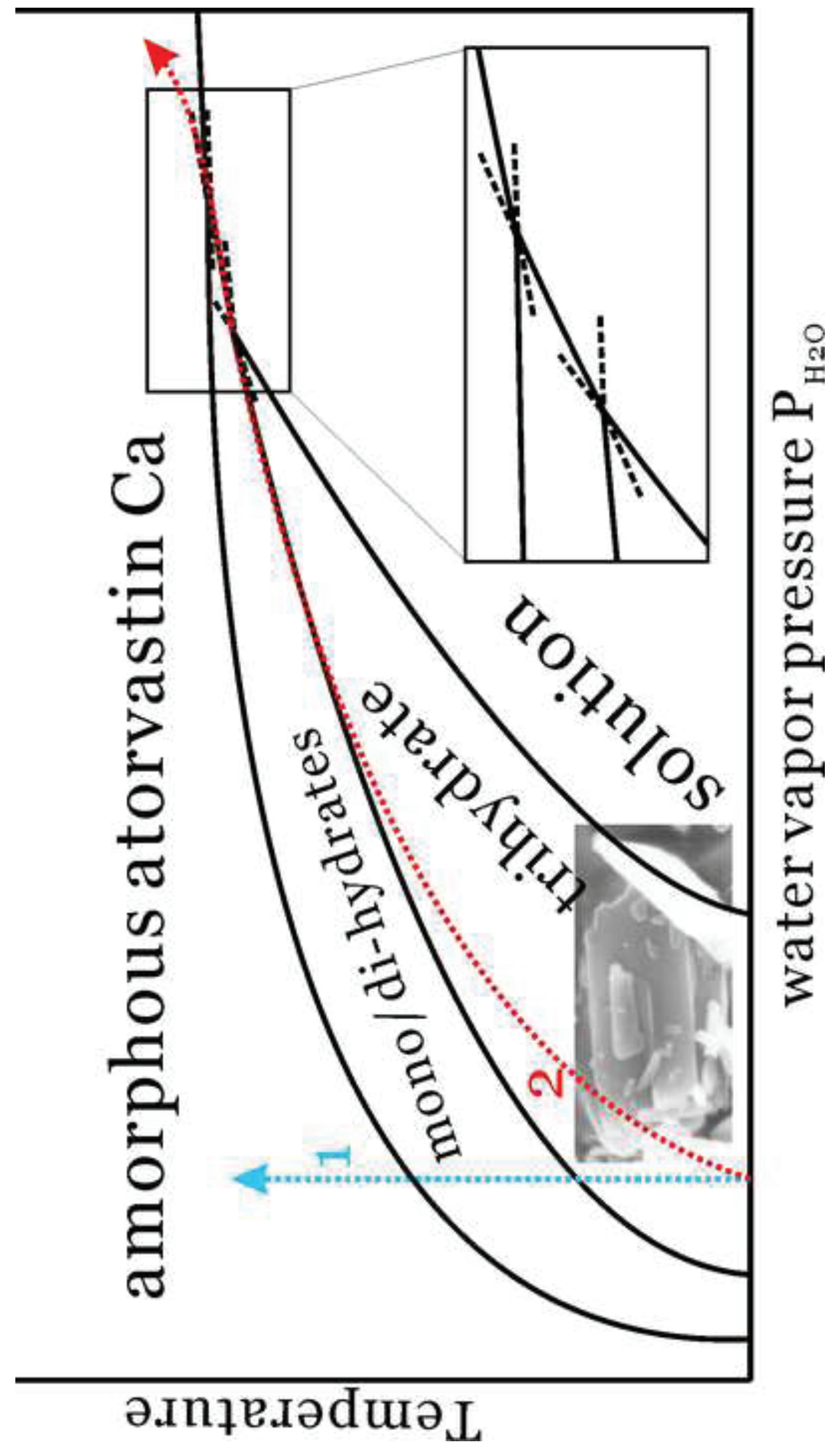




\section{DOES THE TRIHYDRATE OF ATORVASTATIN CALCIUM POSSESS A MELTING POINT?}

Chaima Tizaoui, ${ }^{1,2,3}$ Haykel Galai, ${ }^{2}$ Maria Barrio, ${ }^{4}$ Simon Clevers, ${ }^{1}$ Nicolas Couvrat, ${ }^{1}$ Valérie Dupray, ${ }^{1}$ Gérard Coquerel, ${ }^{1}$ Josep-Lluis Tamarit, ${ }^{4}$ Ivo B. Rietveld ${ }^{1,5,{ }^{*}}$

${ }^{1}$ SMS laboratory (EA 3233), Université de Rouen-Normandie, Place Émile Blondel, 76821 Mont Saint Aignan, France

${ }^{2}$ Laboratory of Materials, Treatment and Analysis (LMTA), National Institute of Research and Physical-chemical Analysis, Technopark of Sidi-Thabet, 2020 Ariana, Tunisia.

${ }^{3}$ Faculté des Sciences de Bizerte, Université de Carthage, 7021 Zarzouna Bizerte, Tunisia.

${ }^{4}$ Grup de Caracterització de Materials, Departament de Física and Barcelona Research Center in Multiscale Science and Engineering, Universitat Politècnica de Catalunya, EEBE, Campus Diagonal-Besòs, Av. Eduard Maristany 10-14, E-08019 Barcelona, Catalonia, Spain.

${ }^{5}$ Faculté de Pharmacie, Université de Paris, 4 avenue de l'observatoire, 75006 Paris, France.

* Corresponding author: ivo.rietveld@univ-rouen.fr 


\section{ABSTRACT}

To decide whether an active pharmaceutical ingredient can be used in its amorphous form in drug formulations, often the glass transition is studied in relation to the melting point of the pharmaceutical. If the glass transition temperature is high enough and found relatively close to the melting point, the pharmaceutical is considered to be a good glass former. However, it is obviously important that the observed melting point and glass transition involve exactly the same system, otherwise the two temperatures cannot be compared. Although this may seem trivial, in the case of hydrates, where water may leave the system on heating, the composition of the system may not be evident. Atorvastatin calcium is a case in point, where confusing terminology, absence of a proper anhydrate form, and loss of water on heating lead to several doubtful conclusions in the literature. However, considering that no anhydrate crystal has ever been observed and that the glass transition of the anhydrous system is found at $144^{\circ} \mathrm{C}$, it can be concluded that if the system is kept isolated from water, the chances that atorvastatin calcium crystallises at room temperature is negligible. The paper discusses the various thermal effects of atorvastatin calcium on heating and proposes a tentative binary phase diagram with water.

Keywords: active pharmaceutical ingredient, thermal properties, glass transition, binary phase diagram, hydrate, kinetic stability 


\section{INTRODUCTION}

Many solid forms have been claimed for atorvastatin, which among others are based on free acid (Campeta et al., 2005) or on a divalent calcium ion (Briggs et al., 1997; Byrn et al., 2003; Krzyzaniak et al., 2006; Krzyzaniak et al., 2011; Mathew and Ganesh, 2002; Suri et al., 2004). The most common solid form of atorvastatin is a trihydrate calcium salt with the ratio $2: 1: 3$, (atorvastatin $\left.{ }_{2}\right)_{2} \cdot \mathrm{Ca}^{2+} \cdot 3 \mathrm{H}_{2} \mathrm{O}\left(\mathrm{ATC} \cdot 3 \mathrm{H}_{2} \mathrm{O}\right.$, see Figure 1$)$. This hydrate is often called atorvastatin form I in the literature or even just atorvastatin (Arunkumar et al., 2009; Asada et al., 2016; Bobe et al., 2011; Choudhary et al., 2012; Dong et al., 2018; Jahan et al., 2013; Jahangiri et al., 2015; Shete et al., 2010), which is deceptive, because besides atorvastatin and calcium the structure contains water and the system is therefore not unary.

From a thermodynamic point of view, it is important to define the system beforehand. It may be practical to define a salt as a 'unary' system such as for atorvastatin calcium, because the interactions between the two ions are often rather strong and there is little risk that either one of the ions will leave the system by evaporation or otherwise and leave the other ion behind to make up the system on its own (it would cause an impossible imbalance in electrical charge). Once in solution, this reasoning may change and it may become important to take the two ions into consideration, but for solid-state formulations this may not be relevant and thus one can in most cases safely define salt forms as unary systems.

In the case of hydrates, or solvates, treating the system as unary is asking for misinterpretation, because water and other solvents tend to evaporate or vice versa to incorporate themselves into crystals through the vapor phase, implying that it is very difficult to maintain a proper, single, well-defined system, because as a function of the humidity in the air the composition of the crystal will shift. It is therefore judicious to clearly define the system as the trihydrate of atorvastatin calcium, or if other trihydrates are discovered "trihydrate of atorvastatin calcium form I". Nonetheless, so far only one fully solved crystal structure with atorvastatin, a solvate containing ethylene glycol, has been described in the Cambridge Structural Database (IZOQIZ) (Adhikari et al., 2016).

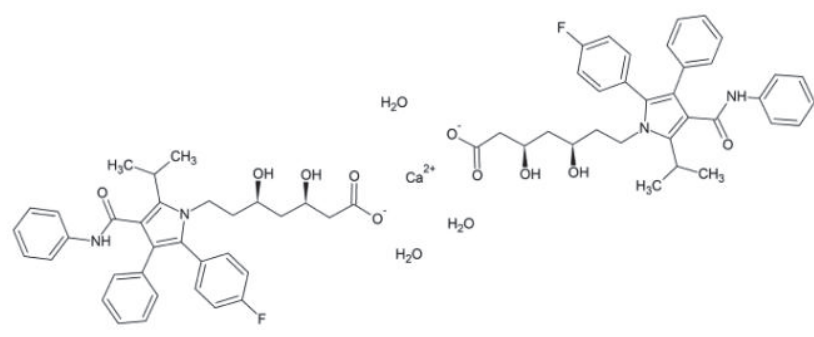

Figure 1. Molecular structure of atorvastatin calcium trihydrate $\left(\mathrm{C}_{66} \mathrm{H}_{68} \mathrm{~F}_{2} \mathrm{~N}_{4} \mathrm{O}_{10} \cdot \mathrm{Ca} \cdot 3 \mathrm{H}_{2} \mathrm{O}\right)$ or $1 \mathrm{H}$-pyrrole-1heptanoic acid, 2-(4-fluorophenyl)- $\beta, \delta$-dihydroxy-5-(1-methylethyl)-3-phenyl-4-[(phenylamino)carbonyl]-, calcium salt, hydrate (2:1:3), $(\beta \mathrm{R}, \delta \mathrm{R})-$, with a molar weight of $1209.39 \mathrm{~g} \mathrm{~mol}^{-1}$.

If a hydrate is heated up, two different melting behaviors can be encountered, either incongruent melting or congruent melting as indicated in Figure 2 for a trihydrate. Congruent melting in the right-hand panel of Figure 2 means that the entire trihydrate forms a liquid with the same composition as that of the trihydrate and such a transition is basically equivalent to fusion of a pure compound. Incongruent melting means that only part of the trihydrate forms a liquid that will be richer in water, therefore creating a "leftover" solid containing more API (active pharmaceutical ingredient) in comparison to the trihydrate. This solid could be another hydrate containing less water, such as a dihydrate or a monohydrate or as assumed in the diagram in Figure 2, a crystalline solid of API without any water. Deciding which of the two types of phase diagrams reflects the behavior of the trihydrate of atorvastatin calcium involves measuring the phase behavior as a function of the temperature for different compositions. A major problem for the trihydrate system of atorvastatin calcium is 
that many of the calorimetric phenomena occur above $100^{\circ} \mathrm{C}$ (Christensen et al., 2013), which implies that water evaporation and the vapor phase need to be considered too.

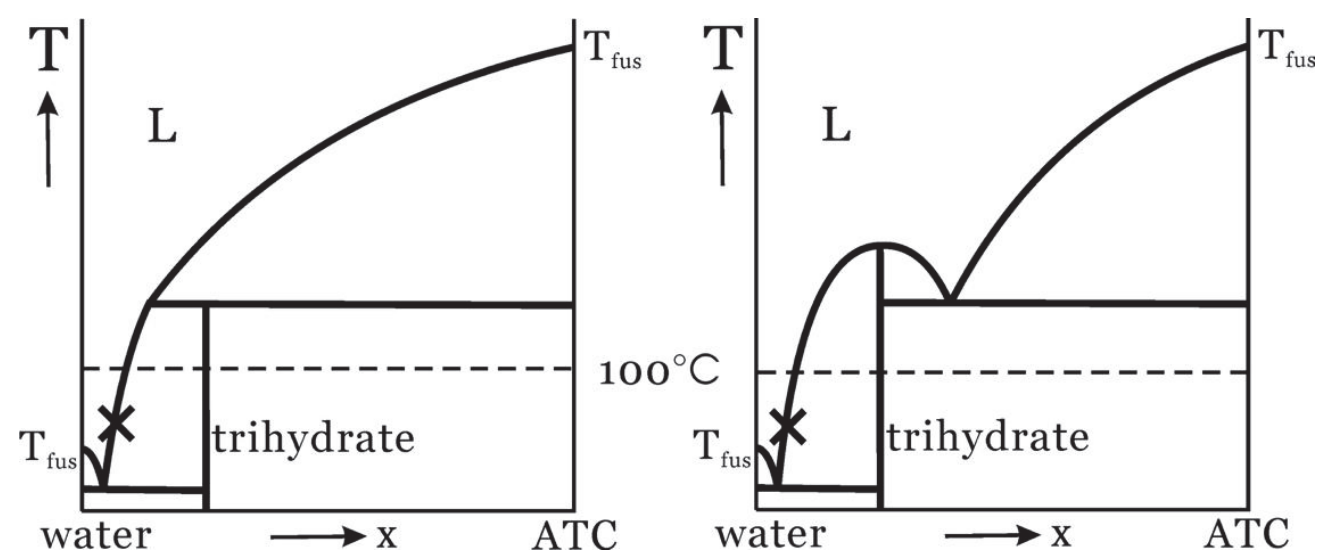

Figure 2. Incongruent (left-hand side) or congruent (right-hand side) melting for a trihydrate in the system water - ATC (ATC: (atorvastatin ${ }_{2}{ }_{2} \cdot \mathrm{Ca}^{2+}$, atorvastatin calcium without water). L: a homogeneous single-phase liquid; dashed line: approximate position of $100^{\circ} \mathrm{C}$; the $\times$ symbol indicates the value on the liquidus line represented by the solubility of the trihydrate around room temperature.

Solubility is part of the phase diagram in Figure 2, because this is the equilibrium value of the maximum concentration of solid phase that dissolves in the liquid phase and it represents therefore a point on the liquidus line around room temperature. In the case of Figure 2, the solubility value at a given temperature, marked by an $\times$, would be found on the curved line left of the vertical line representing the trihydrate. Thus, equilibrium solubility data of ATC would by definition involve the trihydrate, because this is the most stable solid state of ATC in the presence of water.

Solubility data has been collected from the literature and compiled in Table 1. Although in certain papers the solid form was not specifically mentioned or defined by X-ray diffraction, removing a few outliers and disregarding temperature, it can be concluded that the average solubility of ATC $3 \mathrm{H}_{2} \mathrm{O}$ is $157 \pm 79 \mu \mathrm{g} \mathrm{mL}$. This appears to be 10 times lower than the solubility of the sodium form in the table which was developed in the early nineties. This is probably for a large part due to the fact that ATC $\cdot 3 \mathrm{H}_{2} \mathrm{O}$ is a hydrate, which stabilizes this solid form against water dissolution as there is not much to gain in terms of interaction energy.

Table 1. Solubility data of atorvastatin from the literature

\begin{tabular}{|l|l|l|l|l|}
\hline Solid form & $\begin{array}{l}\text { Solubility } \\
\left(/ \mu \mathrm{g} \mathrm{mL}^{-1}\right)\end{array}$ & $\begin{array}{l}\text { Temperature } \\
\left(/{ }^{\circ} \mathrm{C}\right)\end{array}$ & $\mathrm{pH}$ & Ref. \\
\hline ATC $3 \mathrm{H}_{2} \mathrm{O}$ & 124 & 37 & Dist. water & $\begin{array}{l}\text { (Arunkumar } \\
\text { et al., 2009) }\end{array}$ \\
\hline ATC. $3 \mathrm{H}_{2} \mathrm{O} ?^{\mathrm{a}}$ & $4000-5000$ & $\mathrm{RT} ?^{\mathrm{a}}$ & Dist. water & $\begin{array}{l}\text { (Jahan et } \\
\text { al., 2013) }\end{array}$ \\
\hline ATC $3 \mathrm{H}_{2} \mathrm{O}$ & 144.15 & 37 & 6.8 & $\begin{array}{l}\text { (Palanisamy } \\
\text { et al., 2016) }\end{array}$ \\
\hline
\end{tabular}




\begin{tabular}{|c|c|c|c|c|}
\hline ATC $3 \mathrm{H}_{2} \mathrm{O}$ ? $^{\mathrm{a}}$ & 716 & 37 & 7.4 & $\begin{array}{l}\text { (Li et al., } \\
2017)\end{array}$ \\
\hline ATC $\cdot 3 \mathrm{H}_{2} \mathrm{O}$ & 127 & 37 & 6.8 & $\begin{array}{l}\text { (Choudhary } \\
\text { et al., 2012) }\end{array}$ \\
\hline ATC $3 \mathrm{H}_{2} \mathrm{O}$ & 23.5 & 37 & Dist. water & $\begin{array}{l}\text { (Anwar et } \\
\text { al., 2011) }\end{array}$ \\
\hline ATC $\cdot 3 \mathrm{H}_{2} \mathrm{O}$ & 143 & 37 & Dist. water & $\begin{array}{l}\text { (Kim et al., } \\
\text { 2008a; Kim } \\
\text { et al., } \\
\text { 2008b) }\end{array}$ \\
\hline ATC amorphous & 458 & 37 & Dist. water & $\begin{array}{l}\text { (Kim et al., } \\
\text { 2008a; Kim } \\
\text { et al., } \\
\text { 2008b) }\end{array}$ \\
\hline ATC $3 \mathrm{H}_{2} \mathrm{O}$ & 190 & 37 & 6.8 & $\begin{array}{l}\text { (Rodde et } \\
\text { al., 2014) }\end{array}$ \\
\hline ATC amorphous & 843 & 37 & 6.8 & $\begin{array}{l}\text { (Rodde et } \\
\text { al., 2014) }\end{array}$ \\
\hline ATC ? & 210 & RT & water & $\begin{array}{l}\text { (Bobe et } \\
\text { al., 2011) }\end{array}$ \\
\hline ATC $\cdot 3 \mathrm{H}_{2} \mathrm{O}$ & $295.2^{b}$ & 37 & 6.8 & $\begin{array}{l}\text { (Maurya et } \\
\text { al., 2010) }\end{array}$ \\
\hline AT sodium $^{c}$ & 1230 & 30 & 6 & $\begin{array}{l}\text { (Kearney et } \\
\text { al., 1993) }\end{array}$ \\
\hline
\end{tabular}

\footnotetext{
${ }^{\mathrm{b}}$ in the paper given as $\mu \mathrm{g} \mathrm{mL}^{-1}$, but $\mathrm{mg} \mathrm{mL}^{-1}$ is assumed in the Table

${ }^{c}$ for comparison
}

For ATC in the absence of water, two amorphous "forms" are said to exist, of which one has broad peak-like features possessing maxima at $9^{\circ} 2 \theta$ and around $19-20^{\circ} 2 \theta$ and the second amorphous "form" exhibits two 'sharp peaks' at $8^{\circ} 2 \theta$ and at $18^{\circ} 2 \theta$ for $\mathrm{Cu} \mathrm{K \alpha _{1 }}$ radiation (Shete et al., 2010). Some amorphous samples exhibit peaks in the DSC data, which in part may be due to water evaporation and in part have been ascribed to relaxation during the glass transition (Shete et al., 2010), however some of those peaks are rather large and could be interpreted as peaks resulting from fusion of partly crystalline samples with very small crystalline domains causing X-ray diffraction data to appear more or less amorphous (Shete et al., 2010).

The best paper demonstrating what is happening with the trihydrate when heated up is by Christensen et al. who show a clear step-wise loss of the three water molecules by TGA obtained at $1 \mathrm{~K} \mathrm{~min}^{-1}$ followed by decomposition setting in at $170{ }^{\circ} \mathrm{C}$. Using temperature dependent $\mathrm{X}$-ray diffraction and multivariate analysis, they clearly show the relative presence of the trihydrate, dihydrate, and monohydrate as a function of the temperature. Once the water has left, the structure turns into a liquid crystal, a mesophase, which becomes an 
isotropic liquid at around $155^{\circ} \mathrm{C}$ according to the multivariate analysis of the powder $\mathrm{X}$-ray diffraction results (Christensen et al., 2013).

The solid state of atorvastatin has been studied with ${ }^{19} \mathrm{~F}$ solid-state NMR (Asada et al., 2016; Brus et al., 2011; Galai et al., 2015; Urbanova et al., 2013) and a thorough NMR study involving ${ }^{13} \mathrm{C},{ }^{19} \mathrm{~F}$ and ${ }^{15} \mathrm{~N}$ has led to a proposition for the structure of atorvastatin calcium trihydrate in the asymmetric unit with one of the atorvastatin molecules bridging two calcium atoms (Wang et al., 2012). A closer investigation demonstrates that two water molecules also bridge two calcium atoms leaving one water molecule in the trihydrate being bound to a single calcium atom (Holmes et al., 2019). Considering that the unit cell is known (Antonio et al., 2012), this information could help find the full crystalline structure of the trihydrate, which has not been published up to now.

Atorvastatin in the literature appears invariably to be the calcium trihydrate as confirmed by X-ray powder diffraction (Anwar et al., 2011; Arunkumar et al., 2009; Choudhary et al., 2012; Kumar et al., 2016, 2017; Palanisamy et al., 2016; Shete et al., 2010) or amorphous (Redondo et al., 2015; Shete et al., 2010), even if many more forms have been patented (Briggs et al., 1997; Byrn et al., 2003; Campeta et al., 2005; Krzyzaniak et al., 2006; Krzyzaniak et al., 2011; Mathew and Ganesh, 2002; Suri et al., 2004). However, the thermal behavior of the trihydrate of ATC obtained by differential scanning calorimetry (DSC) is often misinterpreted. A typical DSC curve presents often two broad peaks, a smaller one with a maximum roughly around $100^{\circ} \mathrm{C}$ and a larger one with a maximum roughly around $150^{\circ} \mathrm{C}$ (Arunkumar et al., 2009; Bobe et al., 2011; Choudhary et al., 2012; Dong et al., 2018; Kim et al., 2008a; Kim et al., 2008b; Kumar et al., 2016, 2017; Lemsi et al., 2017; Palanisamy et al., 2016; Redondo et al., 2015; Sarkar et al., 2014; Shete et al., 2010; Zhang et al., 2009). The first peak is often ascribed to water loss by the trihydrate through evaporation and the latter peak to the melting of the solid. "Which solid?" is the first question that comes to mind, considering that the crystal water is supposed to have evaporated. In other cases, a rather substantial endothermic effect at around $150{ }^{\circ} \mathrm{C}$ is ascribed to relaxation during a glass transition (Redondo et al., 2015; Shete et al., 2010), which has been observed without any endothermic relaxation at $145{ }^{\circ} \mathrm{C}$ (Lemsi et al., 2017). However, "How could a glass transition temperature and a temperature of fusion be only 5 degrees apart?" is another question that could come to mind. Part of the answer can be found in the paper by Christensen et al. describing the dehydration of ATC. $3 \mathrm{H}_{2} \mathrm{O}$ among other methods through X-ray diffraction as a function of temperature and multivariate analysis (Christensen et al., 2013). The answer for most experimental setups boils down to "there is no melting solid" and the present paper will demonstrate this in terms of a binary phase diagram with the pure components defined as $\mathrm{H}_{2} \mathrm{O}$ and ATC (atorvastatin calcium without any water).

\section{MAterial AND Methods}

\subsection{ATORVASTATIN CALCIUM TRIHYDRATE}

Crystalline atorvastatin calcium trihydrate was kindly provided by the Drugs Quality Control Laboratory of Tunis (Tunisia) and was used without further purification.

\subsection{HOT-STAGE MICROSCOPY EXPERIMENTS}

A Nikon Eclipse LV100 microscope with a maximum magnification of $\times 1000$, equipped with a Linkam THMS 600 hot stage was used to visualize the trihydrate samples while heating. Images were recorded every $5{ }^{\circ} \mathrm{C}$ using a CCD camera Nikon Digital sight DS-Ri1 connected to a computer. The temperature of the hot stage was regulated via the Linksys32 software. 


\subsection{Thermogravimetric Analysis/ Differential Scanning Calorimetry (TGA/DSC) COUPLED TO MASS SPECTROMETRY}

TGA-DSC analysis was performed on a Netzsch STA $449 \mathrm{C}$ instrument. Samples were put in a $25-\mu \mathrm{L}$ aluminum crucible and heated at a rate of $5 \mathrm{~K} \mathrm{~min}^{-1}$. Helium was used as purging gas at a flow rate of $40 \mathrm{~mL} \mathrm{~min}{ }^{-1}$. The chemical nature of escaping gases during heating was identified using a Netzsch QMS 403C mass spectrometer coupled with the TGA apparatus.

\subsection{DifFERENTIAL SCANNING CALORIMETRY}

The differential scanning calorimetry measurements were performed using the NETZSCH DSC 214 Polyma with aluminum crucibles with pierced lids (unless otherwise specified) and pure nitrogen as the purge gas at a flow rate of $40 \mathrm{~mL} \mathrm{~min}^{-1}$. The heating rate was $5 \mathrm{~K} \mathrm{~min}^{-1}$, but was varied between 1 and $50 \mathrm{~K} \mathrm{~min}^{-1}$ for some of the experiments. The DSC is calibrated using mercury, indium, tin, bismuth and zinc.

\subsection{SCANNING ELECTRON MICROSCOPY}

Scanning electron microscopy (SEM) pictures were obtained with a Netscope JCM-5000 instrument (JEOL Europe, Croissy-sur-Seine, France). Crystals were deposited on a SEM stub with double sided carbon tape and coated with gold to reduce charging during analysis.

\subsection{POWDER X-RAY DIFFRACTION}

X-ray powder diffraction (XRPD) was carried out using a high-resolution vertically mounted INEL cylindrical position-sensitive detector (CPS-120, angular step $0.029^{\circ}-2 \theta$ over a $2 \theta$-range from 2 to $115^{\circ}$ ) and a DebyeScherrer geometry equipped with a monochromatic $\mathrm{Cu} \mathrm{K \alpha _{1 }}(\lambda=1.5406 \AA)$ radiation working at $35 \mathrm{kV}$ and 35 $\mathrm{mA}$. The system was equipped with a liquid nitrogen 700 series Cryostream Cooler (Oxford Cryosystems) with an accuracy of $0.1 \mathrm{~K}$. Samples were placed into $0.5-\mathrm{mm}$-diameter Lindemann capillaries, which were rotating around their axes during data collection to reduce the effects of preferential orientation.

\subsection{TEMPERATURE-RESOLVED SECOND HARMONIC GENERATION (TR-SHG)}

An Insight X3 single laser with automated dispersion compensation (Spectra-Physics, Santa Clara, USA) and a TCS SP8 MP confocal microscope (Leica Microsystems, Wetzlar, Germany) were used to carry out confocal microscopy as well as two-photon microscopy on the samples. The laser delivers over $2.54 \mathrm{~W}$ of average power at $900 \mathrm{~nm}$ and is tunable from $680 \mathrm{~nm}$ to $1300 \mathrm{~nm}$. The pulse rate is $80 \mathrm{MHz}$ and the temporal width at the output of the cavity is around $120 \mathrm{fs}$ (<100fs between $850 \mathrm{~nm}$ and $1050 \mathrm{~nm}$ ). The laser is controlled by LASX Leica software. Two Leica hybrid descanned detectors (HyD) were used to record images. Long working distance dry Leica objectives (HC PL Fluotar 5X NA 0.15, HC PL Fluotar 10X NA 0.3 or HC PL APO 20X NA 0.4 CS2) or oil- immersion Leica objective (HC PL APO 40X NA 1.30 CS2) were used. An electro-optical modulator was used to adjust the laser power at the entrance of the confocal system. The spectral acquisition was performed using an internal hybrid detector. Collected photons were dispersed by a prism and a specific motorized split mirror selecting the detected spectral band in front of the hybrid detector. Acquisitions were performed at $450 \mathrm{~nm}$ with a spectral bandwidth of $20 \mathrm{~nm}$.

The samples (a few mg of powder in a crucible) were placed in a computer-controlled heating-cooling stage (Linkam THMS-600) with an accuracy of $0.1^{\circ} \mathrm{C}$ on the temperature control, while the SHG signal was monitored as a function of the temperature. 


\section{RESULTS}

\subsection{ATC $\cdot 3 \mathrm{H}_{2} \mathrm{O}$ CRYSTALS}

A scanning electron microscopy image of crystals of the ATC $3 \mathrm{H}_{2} \mathrm{O}$ sample is provided in Figure 3 . The crystals have different sizes with lengths ranging from 1 to $5 \mu \mathrm{m}$ and thicknesses in the order of $0.5-1 \mu \mathrm{m}$ and it can be observed that the crystals form agglomerates consisting of smaller crystallites.

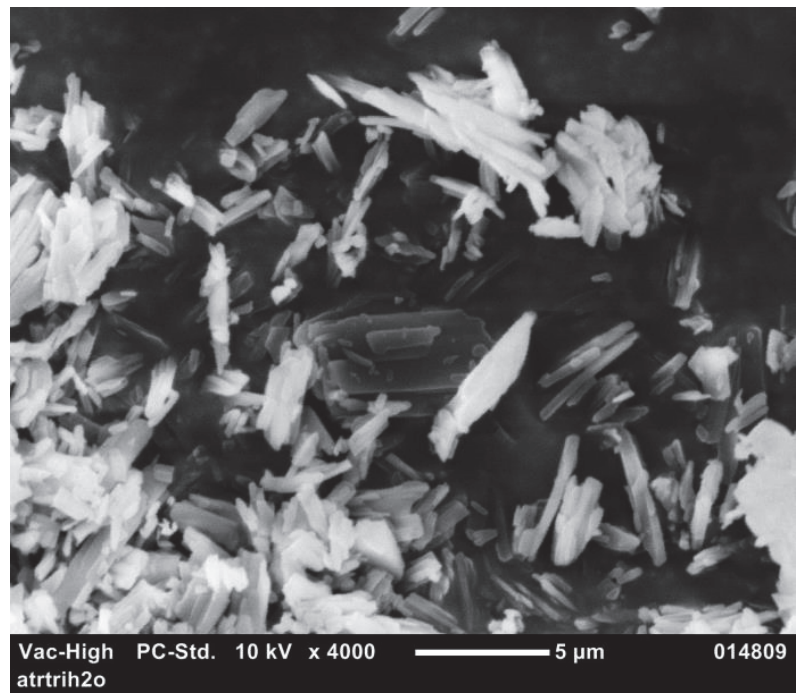

Figure 3. Scanning electron microscope photo of the current batch of atorvastatin calcium trihydrate

\subsection{TherMOgRAVIMETRY OF ATC $\cdot 3 \mathrm{H}_{2} \mathrm{O}$}

The thermogravimetric curve obtained in combination with the DSC curve demonstrates that weight loss starts around $40^{\circ} \mathrm{C}$ under a dry helium gas atmosphere combined with an endothermic heat exchange (Figure 4). The signal of the mass spectrometry coupled to the TGA demonstrates that the loss is linked to water evaporation (Figure S1d). A highly convoluted second and third peak exhibits an onset at about $110^{\circ} \mathrm{C}$ (Figure S1b), which indicates that part of the water molecules is strongly bound as they leave the crystal lattice above the boiling point of water. Solid-state NMR results in the literature indicate that two water molecules bridge two divalent calcium ions (Holmes et al., 2019), which most likely explains the high temperature at which these two molecules leave the crystal. The water loss peak below $100{ }^{\circ} \mathrm{C}$ is most likely related to the loss of the water molecule bound to a single calcium ion (Holmes et al., 2019; Mahe et al., 2013; Wang et al., 2012).

The mass loss for the first step is $1.7 \%$ (Figure 4). Considering that the molar weight of the trihydrate containing two atorvastatin moieties and one calcium ion equals $1209.39 \mathrm{~g} \mathrm{~mol}^{-1}, 1.7 \%$ represents $20.6 \mathrm{~g}$ and with the molar weight of water being $18.015 \mathrm{~g} \mathrm{~mol}^{-1}$, it is clear that about one molecule of water leaves the system in the first step. The total amount of water loss is $4.2 \%$, which is equal to 2.8 molecules of water in total of which in the second step 1.7 water molecules are lost. It is clear from these calculations and the shape of the peaks that the loss of water happens with a lot of overlap between the different stages. This is probably due to the TGA scan rate, the differences in particle size as can be seen in Figure 3 and the respective amount of surface area in relation to the bulk. The enthalpy of the peaks involving complete water loss equals $144.2 \mathrm{~J}$ $\mathrm{g}^{-1}$ of total sample weight (Figure S1c) or $58 \mathrm{~kJ} \mathrm{~mol}^{-1}$ of evaporating water.

A small peak can be observed with an onset at $152.8^{\circ} \mathrm{C}$ that does not seem to be related to any mass loss as indicated by the simultaneous horizontal segment in the TGA curve. Its enthalpy is endothermic, ca. $6 \mathrm{~J} \mathrm{~g}^{-1}$, according to the TGA/DSC measurements (Figure S1c). 
The broad DSC peak in Figure 4 with a maximum around $210{ }^{\circ} \mathrm{C}$ and the gradual decline of the mass in the TGA curve starting around $180^{\circ} \mathrm{C}$ must be due to decomposition of atorvastatin as both water (Figure S1d) and an increase in $\mathrm{CO}_{2}$ (not shown) can be detected in the gasses lost by the sample.

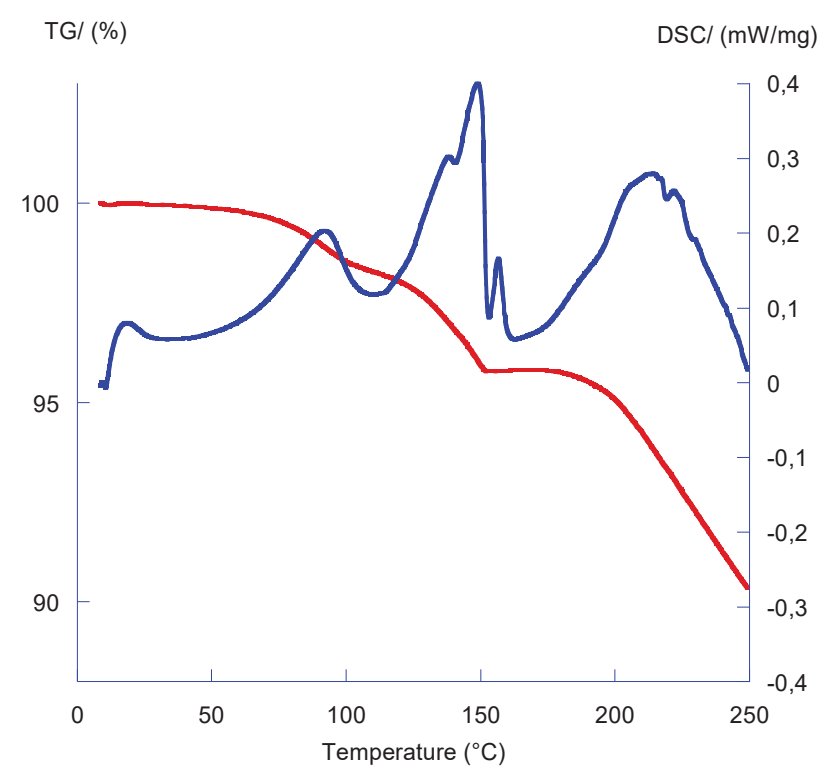

Figure 4. Weight loss of ATC $3 \mathrm{H}_{2} \mathrm{O}$ as a function of temperature of atorvastatin calcium hydrate measured by thermogravimetric analysis under a flow of dry helium (DSC curve endo up). Heating rate $5 \mathrm{~K} \mathrm{~min}^{-1}$. The registered weight loss of $4.18 \%$ at $160^{\circ} \mathrm{C}$ coincides with the loss of 2.8 water molecules per ATC unit. Left-hand axis: red curve, relative weight in relation to the initial weight (100\%), right-hand axis: blue curve, DSC signal.

\subsection{THE EFFECT OF HEATING RATE ON WATER LOSS}

In Figure 5, DSC curves can be found of ATC $3 \mathrm{H}_{2} \mathrm{O}$ obtained at heating rates of 1, 2, 5, 10, 20, and $50 \mathrm{~K} \mathrm{~min}{ }^{-1}$. At $10 \mathrm{~K} \mathrm{~min}^{-1}$ and higher, two broad endothermic peaks can be observed. These peaks slowly separate into three maxima at lower heating rates suggesting a stepwise loss of the approximately three water molecules similar to the TGA (Figure 4). It can also be seen that the slower the heating rate, the lower the temperature at which the largest peak has returned back to the baseline (Figure 5). Considering the TGA result connecting this large peak with the loss of two water molecules, it implies that with a slower heating rate, the crystal water has left the system at a lower temperature. For a negligible heating rate this temperature tends to about $130{ }^{\circ} \mathrm{C}$ as can be seen in the graph in Figure 6 . The onset of the loss of the first water molecule extrapolated to zero heating rate is found at around $40^{\circ} \mathrm{C}$, just above room temperature demonstrating that the trihydrate will be stable under ambient conditions and sufficient humidity, but some crystal water may leave under low humidity and high ambient temperatures. The onset of the departure of the third water molecule at zero heating rate is found around $105{ }^{\circ} \mathrm{C}$, which closely coincides with the results of the multivariate analysis of Christensen et al. carried out at $1{ }^{\circ} \mathrm{C} \mathrm{min}{ }^{-1}$ and who find about $110{ }^{\circ} \mathrm{C}$ for the onset temperature reported in Figure 8 a of reference (Christensen et al., 2013).

The positions of these two peaks are clearly affected by the heating rate, strongly indicating that they are not related to melting. Melting being an endothermic order-disorder transition is not affected by any substantial activation barrier. Heat necessary for melting will be provided by the DSC and while melting takes place the system will remain at its melting temperature until the system has turned into liquid; hence a melting peak of a pure compound will not change significantly with heating rate assuming a proper calibration of the DSC equipment. An example of a constant melting point with changing heating rate can be found in reference (Barrio et al., 2012). The average enthalpy of the loss of a water molecule as measured by the DSC is in the order of $74 \mathrm{~kJ} \mathrm{~mol}^{-1}$ of evaporating water, which is somewhat higher than obtained by the ATG/DSC. However, 
it can be seen in Table S1 that the fluctuations on the enthalpy values are quite large so that both the TGA and the DSC results are comparable within error.

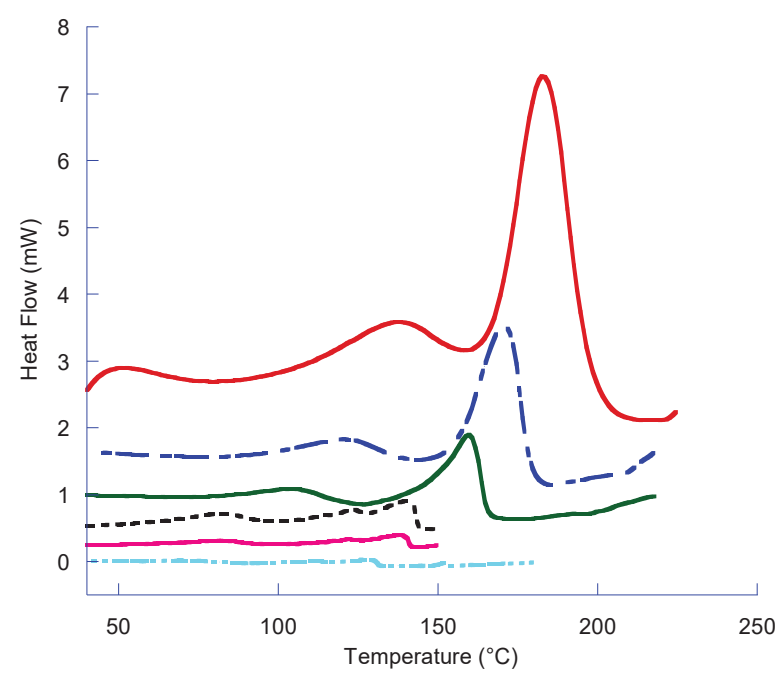

Figure 5. DSC curves (endo up) of the trihydrate of atorvastatin calcium for different heating rates obtained from samples in a pierced DSC pan. From the bottom upwards the heating rate is 1, 2, 5, 10, 20, $50 \mathrm{~K} \mathrm{~min}^{-1}$.

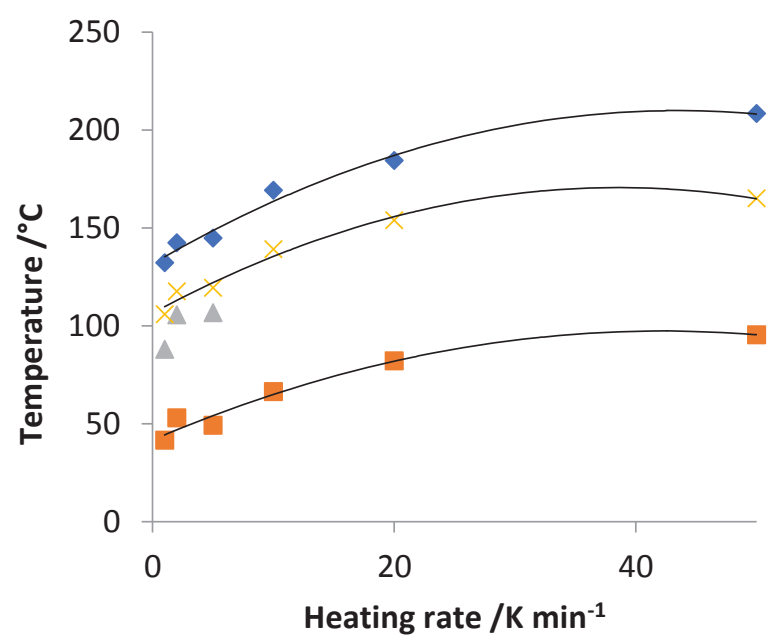

Figure 6. Onset and endpoint temperatures for the water loss peaks of the trihydrate as a function of the heating rate in the DSC with pierced DSC pans, squares: onset temperature of the departure of the first water molecule, triangles: onset temperature for the second water molecule, crosses: onset temperature of third (and second) water molecule, diamonds: end point temperature of the water departure

\subsection{THE FINER DETAILS AFTER WATER LOSS}

After the water loss, a small peak was observed in the DSC signal of the TGA measurement, while the TGA signal demonstrated no loss of mass (Figure 4). A similar peak has been observed in the DSC measurements, if the heating rate was low enough for the water loss peaks not to overlap with this small effect. For heating rates of $5 \mathrm{~K} \mathrm{~min}^{-1}$ and below, by stopping the measurement at $150^{\circ} \mathrm{C}$, cooling and reheating at the same heating rate, the small peak could be clearly observed (Figure 7). This is an additional strong indication that the peak does not involve the evaporation of water, because in that case stopping the measurement at $150^{\circ} \mathrm{C}$ and turning back would have left enough time for the system to release remaining crystal water as can be concluded from the zero heating rate results (Figure 6). The peak maintains a similar enthalpy of about $6 \mathrm{~J} \mathrm{~g}^{-1}$ 
with an onset temperature of $147.3{ }^{\circ} \mathrm{C}$ for the heating rates of 1 and $2 \mathrm{~K} \mathrm{~min}^{-1}$. At $5 \mathrm{~K} \mathrm{~min}^{-1}$ the onset temperature is slightly higher at $152.9^{\circ} \mathrm{C}$.

Measurements by DSC at $5 \mathrm{~K} \mathrm{~min}^{-1}$, stopping the measurement at $150^{\circ} \mathrm{C}$ and opening the capsule demonstrate that the sample has not liquefied (Figure S2). Interrupting the heating run at $160^{\circ} \mathrm{C}$ results in a similar appearance, however, the sample does appear more coagulated, which could be interpreted as the onset of a very viscous liquid (Figure S2).

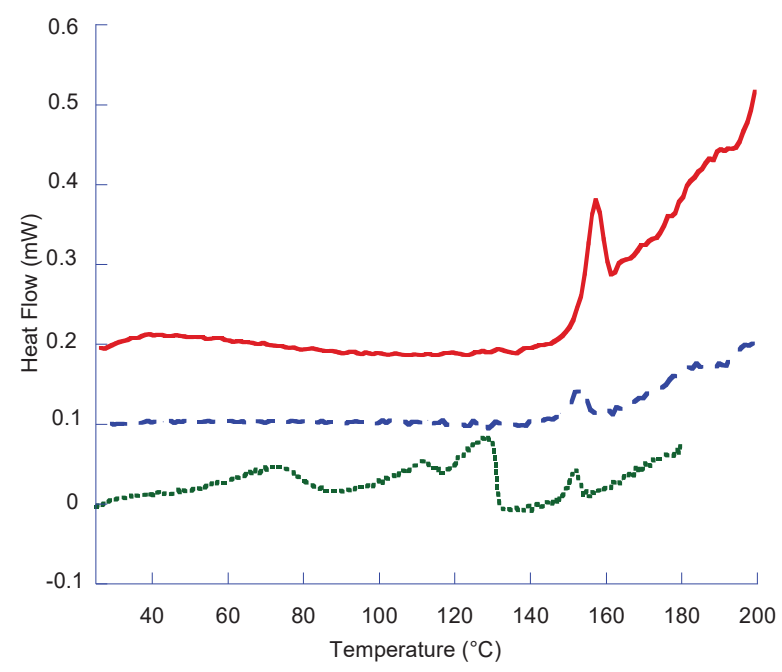

Figure 7. The small peak following the large water loss peaks from bottom to top 1,2 , and $5 \mathrm{~K} \mathrm{~min}^{-1}$. In the case of 2 and $5 \mathrm{~K} \mathrm{~min}^{-1}$ the curve has been obtained by a DSC scan up to $150{ }^{\circ} \mathrm{C}$ followed by cooling down, and reheating with the same heating rate.

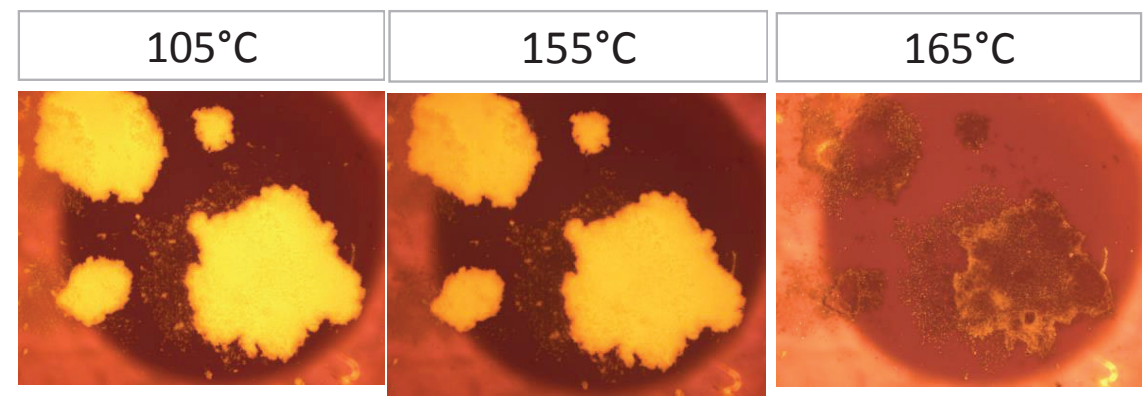

Figure 8. Liquifying atorvastatin calcium (trihydrate) under the microscope using polarized light: temperature increase from 105 to $180{ }^{\circ} \mathrm{C}$ with $1 \mathrm{~K} \mathrm{~min}^{-1}$. Darkening indicates loss of crystallinity, due to an increase in the isotropy in the sample.

It can be seen in Figure 7 that besides the small peak of $6 \mathrm{~J} \mathrm{~g}^{-1}$ no other thermal event occurs in the heating runs at 2 and $5 \mathrm{~K} \mathrm{~min}^{-1}$, once the crystal water has been removed. However, if a trihydrate sample is heated to $180^{\circ} \mathrm{C}$, cooled and then reheated at $5 \mathrm{~K} \mathrm{~min}^{-1}$, a glass transition temperature of ATC in absence of water can be found at $144{ }^{\circ} \mathrm{C}$ (observed in several measurements in cooling and heating runs). As this glass transition is clearly not present in Figure 7 ( for 2 and $5 \mathrm{~K} \mathrm{~min}^{-1}$ ), it indicates that water loss alone does not immediately lead to a fully vitreous sample. Moreover, the DSC sample in Figure S2 heated up to $150^{\circ} \mathrm{C}$ would have had to become liquid above $144^{\circ} \mathrm{C}$. In Figure S3, this can also be seen with a sample heated at $5 \mathrm{~K} \mathrm{~min}^{-1}$ up to $190^{\circ} \mathrm{C}$ and cooled at the same rate. A glass transition can be observed at $143^{\circ} \mathrm{C}$ in the cooling run, some 10 degrees lower than the onset of the small peak. It is therefore highly likely that the small peak of $6 \mathrm{~J} \mathrm{~g}^{-1}$ is not a glass transition in itself, but it may represent a kind of melting transition, because after its occurrence on cooling a glass transition is observed. 
The observations of atorvastatin under the microscope (Figures 8 and S4) as a function of temperature demonstrate that the sample darkens at around $155^{\circ} \mathrm{C}$ and is completely molten around $165^{\circ} \mathrm{C}$. In figure $\mathrm{S} 5$, a comparison between two samples quickly heated under the microscope, one covered and the other not, shows the appearance of two phases for the covered sample as it liquifies on heating. This is indicative of incongruent melting.

\subsection{CRYSTALLINITY AS A FUNCTION OF THE TEMPERATURE by SHG AND X-RAY DIFFRACTION}

Because atorvastatin is a chiral molecule, which in fact is a pure enantiomer $(\beta R, \delta R$, see Figure 1$)$, its crystal system in the hydrate is non-centrosymmetric (NC). The system is postulated to be $\mathrm{P} 1$, but this has not been verified yet by a known structure (Antonio et al., 2012). The non-linear optical effect SHG only occurs in NC crystal structures. Thus, SHG is extremely sensitive to the detection of the presence of NC crystals and can be used to monitor phase transitions from NC crystals to centrosymmetric or isotropic phases, in which SHG cannot occur, and this method has been previously applied to the monitoring of dehydration processes (Poupon et al., 2015) and the presence of a few ppm of an NC structure can be detected by SHG (Clevers et al., 2013). For a sample of atorvastatin trihydrate the SHG signal has been plotted as a function of the temperature starting at $25^{\circ} \mathrm{C}$, while heating with a rate of $1 \mathrm{~K} \mathrm{~min}^{-1}$ (Figure 9).

It can be seen that while heating the sample the SHG signal increases somewhat followed by a minimum at $90^{\circ} \mathrm{C}$. With the information obtained from the DSC and TGA measurements, it is clear that water loss occurs in this temperature range. The SHG signal demonstrates that the structure itself is not really affected by the water loss. Above $90^{\circ} \mathrm{C}$, where the second water molecule is set to leave according to the DSC data (Figure 6) the SHG signal increases even somewhat (Figure 9), which is related to modifications in the crystallinity due to the water loss; however, it clearly shows that crystallinity is maintained until the last water molecule starts leaving the crystal.

At around $123^{\circ} \mathrm{C}$, the effect of the remaining water molecule leaving starts to negatively affect the SHG signal, which descends rapidly, indicating a sustained loss of crystallinity. A shoulder can be observed similar to the DSC and TGA data. A major part of the SHG signal has disappeared at about $141{ }^{\circ} \mathrm{C}$, which is somewhat higher than in the DSC, where a value of $132^{\circ} \mathrm{C}$ has been found. Interestingly, a small SHG signal can still be observed, indicating the presence of a remainder of a crystal structure that is non-centrosymmetric. The signal fades out at $154^{\circ} \mathrm{C}$, which is at the same temperature $\left(T_{\max }\right)$ as the small $6 \mathrm{~J} \mathrm{~g}^{-1}$ peak observed in the TGA and in the DSC, which is an indication that this small peak is a type of melting transition (i.e. order $\rightarrow$ disorder) albeit of a weakly crystalline system.

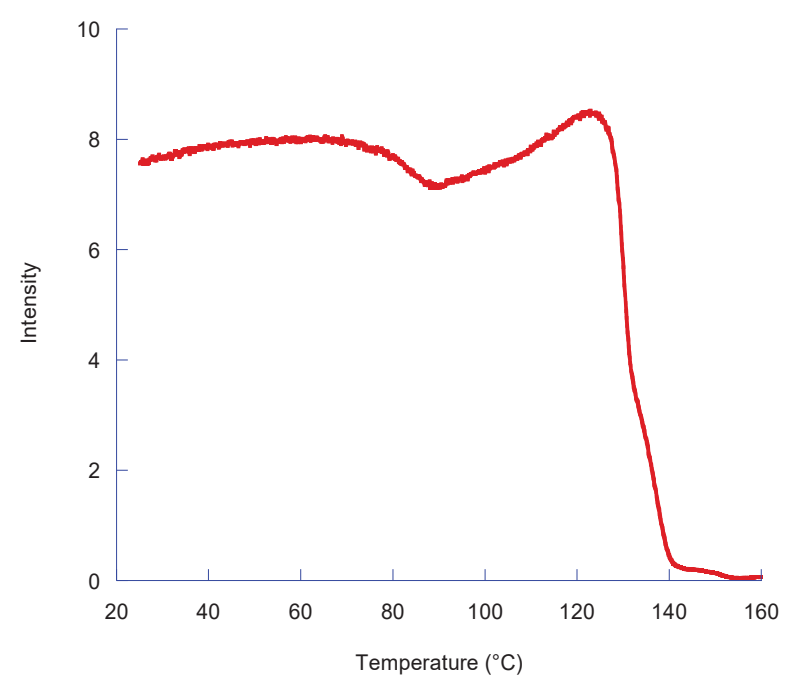


Figure 9. Second harmonic generation $(450 \mathrm{~nm}$ ) by laser light excitation at $900 \mathrm{~nm}$. Dehydration followed by SHG at $1 \mathrm{~K} \mathrm{~min}^{-1}$.
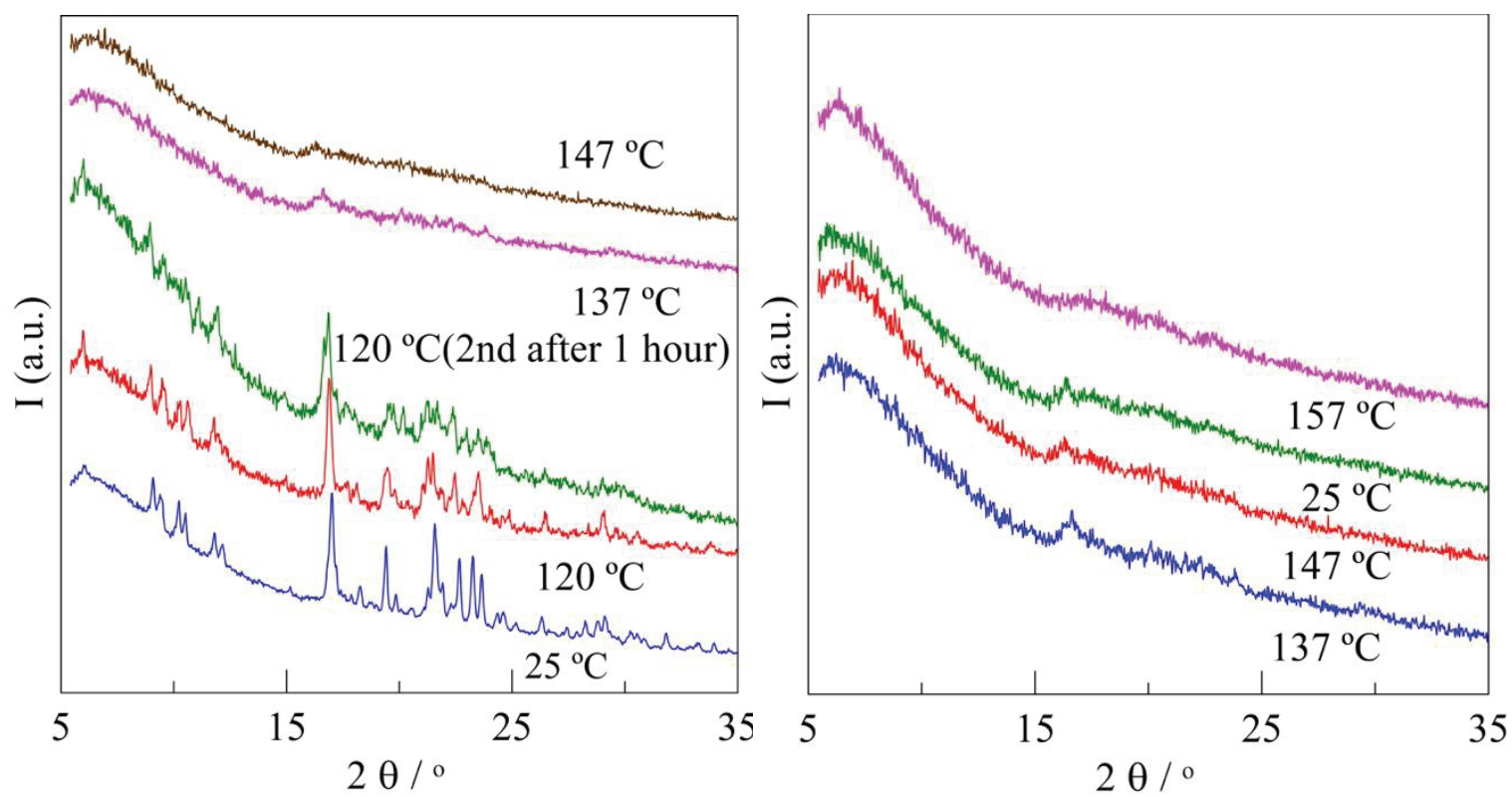

Figure 10. X-ray diffraction of the trihydrate as a function of temperature. Left-hand panel: blue curve room temperature, red curve $120^{\circ} \mathrm{C}$, green curve $2^{\text {nd }}$ measurement after one hour, pink curve $137^{\circ} \mathrm{C}$, brown curve $147^{\circ} \mathrm{C}$. Right-hand panel: blue curve $137^{\circ} \mathrm{C}$, red curve $147^{\circ} \mathrm{C}$, green curve RT after the measurement at $147^{\circ} \mathrm{C}$, pink curve $157^{\circ} \mathrm{C}$.

X-ray diffraction of atorvastatin has been carried out as a function of temperature (Figure 10). At room temperature, the diffraction pattern is equal to that of the trihydrate. After heating to $120^{\circ} \mathrm{C}$, the main peaks of the structure remain and a displacement due to thermal expansion can be observed similar to the observations by Christensen et al. (Christensen et al., 2013). At $137{ }^{\circ} \mathrm{C}$, most of the structure has gone according to the X-ray diffraction; however, the large peak at around $17^{\circ} 2 \theta$ is still visible, indicating the presence of a remainder of the crystalline phase as observed by SHG. Once $157^{\circ} \mathrm{C}$ has been reached any trace of a crystalline phase has disappeared in line with the SHG signal.

From the foregoing results, it can be concluded that the trihydrate loses water molecules in a stepwise manner through heating even if the crystallinity up to the monohydrate is clearly maintained (Figures 9 and 10). Once the last water molecule leaves, crystallinity is quickly lost, although some long-range structure capable of generating SHG remains, which subsequently "melts" to form a homogeneous liquid made up of ATC.

\subsection{HeAting ATC $\cdot 3 \mathrm{H}_{2} \mathrm{O}$ under SATURATEd WATER VAPOR PRESSURE}

A measurement has been carried out in a closed DSC capsule containing the trihydrate. A capsule was used that could resist the vapor pressure of water. It can be seen in Figure 11 that if water is not allowed to leave the capsule, the baseline remains flat up to about $115^{\circ} \mathrm{C}$, where a slight increase can be observed due to evaporation of some water from the trihydrate as a result of the vapor pressure equilibrium between the trihydrate and the water vapor inside the capsule at a given temperature. In fact, the rise of the baseline represents about $20 \mathrm{~J} \mathrm{~g}^{-1}$ or $24 \mathrm{~kJ} \mathrm{~mol}^{-1}$ of trihydrate, which (related to about $70 \mathrm{~kJ}$ per mole of evaporating water from the hydrate as determined in sections 3.2 and 3.3 ) implies that about $30 \%$ of the trihydrate has lost a water molecule before the hydrate mixture melts. While the water vapor pressure clearly increases with the temperature, indicated by the change of slope of the baseline from $115{ }^{\circ} \mathrm{C}$ on, a sharp peak can be 
observed with an onset of $154.9^{\circ} \mathrm{C}$ and an enthalpy of $130 \mathrm{~J} \mathrm{~g}^{-1}$. Because the peak comes neatly down to its baseline, it is obviously involved in an equilibrium where the trihydrate transforms into another phase, and taking the enthalpy involved into consideration this phase is most likely a liquid with or without a solid ATC component (see Figure 2, congruent or incongruent melting). No recrystallisation occurred in the sample and the opened capsule, after it was determined that no weight loss had taken place during the measurement, clearly showed a vitreous state inside indicating that a melting transition had taken place. A few measurements with regular capsules at low temperature and with added water led to a eutectic temperature between water and the trihydrate of $-0.6{ }^{\circ} \mathrm{C}$, quite close to the melting point of water. No Tammann curve or eutectic point could be determined due to the low solubility of ATC $3 \mathrm{H}_{2} \mathrm{O}$ in water.

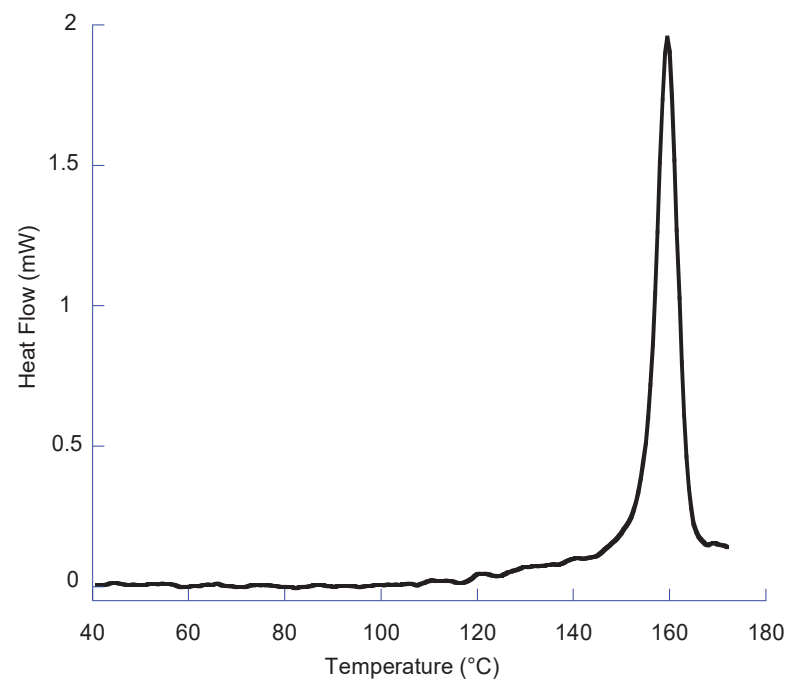

Figure 11. DSC curve of atorvastatin calcium trihydrate in a closed capsule (endothermic up)

\section{DISCUSSION}

\subsection{HOW COULD THE OBSERVED CALORIMETRIC BEHAVIOR BE INTERPRETED?}

The answer depends on the conditions of the sample. In the scenario that is provided in the paper of Christensen et al. (Christensen et al., 2013) and that is valid for all TGA measurements and for many DSC measurements in the literature, melting does not occur (or only partially, while mixed with the signal of water evaporation). Heating the trihydrate will increase the water vapor pressure of the hydrate; however, the water vapor in the surroundings in open air will be limited by the maximum amount of water that can dissolve in air at room temperature (TGA measurements under a dry carrier gas will intensify this effect). Once the temperature has reached the threshold at which the vapor pressure of the trihydrate is not compensated anymore by the surrounding vapor pressure in the air, the trihydrate will start to lose water. This is indicated by the vertical dotted arrow marked by ' 1 ' in Figure 12 in the left-hand graph where a schematic ideal phase diagram is provided of the phase equilibria between the trihydrate and the hypothetical anhydrate and between the trihydrate and its solution. For the sake of clarity, the other two hydrates have been left out. The moment arrow 1 crosses the equilibrium line between the trihydrate and the anhydrate (as a function of $T$ and $\mathrm{P}_{\mathrm{H} 2 \mathrm{O}}$ ), the trihydrate will cease to be stable. It will turn in a stepwise manner into a dihydrate, a monohydrate and then into an anhydrate phase, although in reality these forms will coexist. In the binary phase diagram on the right-hand side in Figure 12, this process is indicated by the dotted line marked with ' 1 ', in which water can be seen to gradually leave the system (several dehydration pathways can be found in the following references (Galwey, 2000; Petit and Coquerel, 1996)). 
What happens to the anhydrous ATC phase? It is not altogether forming a glassy state as indicated by the remaining SHG signal at $141{ }^{\circ} \mathrm{C}$, the remaining peaks in the X-ray diffraction data, and the absence of a glass transition. Some long range order appears to remain in combination with a rigidity or very high viscosity and this corresponds to the definition of a mesophase as an intermediate between a crystal and an isotropic liquid (de Gennes and Prost, 1993) and to the observation by Christensen et al. that at $140{ }^{\circ} \mathrm{C}$ ATC forms a mesophase, which turns into a isotropic liquid at $155^{\circ} \mathrm{C}$ (Christensen et al., 2013). The latter clearly coincides with the small peak with an onset at $147^{\circ} \mathrm{C}$ and with an enthalpy of $6 \mathrm{~J} \mathrm{~g}^{-1}$ and thus an entropy of $16.5 \mathrm{~J} \mathrm{~K}^{-1}$ $\mathrm{mol}^{-1}$. Such enthalpy and entropy values are comparable to other mesophases turning into an isotropic liquid (Morale et al., 2003; Pramanik et al., 2013).

Considering the 'two' amorphous phases of atorvastatin calcium mentioned in the literature (Shete et al., 2010), the present observations by X-ray diffraction and SHG as a function of the temperature and the information provided by Christensen et al. about the mesophase,(Christensen et al., 2013) it seems evident that one of the 'amorphous phases' is in fact the vitreous version of the mesophase with a peak around $17-18^{\circ}$ 2 $\theta$. If this sample is heated up to $160{ }^{\circ} \mathrm{C}$, the mesophase will turn into the isotropic melt and become a truly amorphous form.

The second scenario is the melting of the trihydrate in the closed DSC capsule. The system follows the curved dotted trajectory marked by ' 2 ' in the $T-\mathrm{P}_{\mathrm{H} 2 \mathrm{O}}$ phase diagram. To maintain a saturated water vapor pressure, part of the water contained in the trihydrate will evaporate and some of the trihydrate will therefore change into the dihydrate, but because a limited amount of water is needed to fill up the dead space of the capsule, most of the trihydrate will continue to be stable up to its melting point. The water evaporation from the trihydrate can be observed by the gradual increase of the baseline in Figure 11 . At $155.8{ }^{\circ} \mathrm{C}$, the trihydrate reaches its equilibrium point with the liquid phase, which is either congruent or incongruent melting. This temperature is very close to the observed melting peak of the mesophase of $6 \mathrm{~J} \mathrm{~g}^{-1}$ with an onset of $147.3^{\circ} \mathrm{C}$ (at $1 \mathrm{~K} \mathrm{~min}^{-1}$ in DSC) and to the observed glass transition of $144{ }^{\circ} \mathrm{C}$. However, it is a different transition and equilibrium. This can be seen in the binary phase diagram, in which the melting of the trihydrate in a closed capsule is indicated by the dotted line marked with a 2 . Ideally, the system would remain on the vertical line indicating the trihydrate, but because of loss of some water to maintain the water vapor pressure in the capsule at saturation a deficit in water in the solid phase occurs (see the gradually rising baseline in Figure 11). What is difficult to ascertain however, is whether this melting equilibrium involves congruent or incongruent melting due to the inability of ATC to quickly crystallize into an anhydrous crystalline form and because of the tendency of ATC to decompose at temperatures above the melting point of the trihydrate. Nonetheless, the appearance of two liquid domains under the microscope while quickly heating the sample under closed conditions in Figure S5 does point to incongruent melting behavior (and because ATC does not crystallize this could result in a metastable syntectic phase equilibrium).

On the water-rich side of the binary phase diagram (Figure 12b), the horizontal eutectic line can be found at $-0.6{ }^{\circ} \mathrm{C}$ and the curved liquidus line of the trihydrate must pass through the composition of $0.157 \mathrm{mg} \mathrm{mL}^{-1}$ (the average solubility of $\mathrm{ATC} \cdot 3 \mathrm{H}_{2} \mathrm{O}$ ) at around $37^{\circ} \mathrm{C}$.

\subsection{THE GLASS TRANSITION AT $144^{\circ} \mathrm{C}$ IN RELATION TO THE OBSERVED THERMAL EVENTS IN}

\section{THE ATORVASTATIN CALCIUM HYDRATE SYSTEM}

The glass transition is expected to be $2 / 3$ of the melting temperature in kelvin, the so-called BeamanKauzmann rule (Gutzow and Schmelzer, 2013). Although, this rule is empirical, it does have a physical background in the sense that the viscosity and density of the undercooled liquid must have reached critical values, which do not occur very close to the melting point (Gutzow and Schmelzer, 2013). Moreover, a crystal is necessarily more stable than the vitreous state and $\mathrm{T}_{\mathrm{g}}$ for a properly defined system must therefore always lie below the melting point. The reason that in the present case, the glass transition temperature and the 
melting temperature exhibit a difference of ten degrees is not a physical anomaly, but simply the result of the fact that the melting point of $155.8^{\circ} \mathrm{C}$ and the glass transition at $144^{\circ} \mathrm{C}$ involve two different systems. The first is the melting of the trihydrate, which contains water and the latter is the glass transition of anhydrous ATC (Figure 12b). There exists therefore no direct relationship between the two.

In fact, using the empirical rule of $\mathrm{T}_{\mathrm{g}}=2 / 3 \mathrm{~T}_{\text {fus, }}$ one can estimate the melting point of a so-far hypothetical anhydrous crystalline ATC to be about $626 \mathrm{~K}\left(353^{\circ} \mathrm{C}\right)$. This form has never been observed to our knowledge and will have a hard time crystallizing apparently, but with such a high temperature the stable phase diagram will most likely possess an incongruent melting equilibrium with a peritectic equilibrium as represented in Figure 12b. The fact that pure ATC does not crystallise implies that the peritectic transition is not complete and that amorphous ATC will form while melting (see Figure S5), which due to its $\mathrm{Tg}$ will be a metastable liquid. This is schematically depicted in Figure $12 \mathrm{~b}$ by the upward dashed line slightly curving away from the pure ATC axis. At the water-rich side of the phase diagram a similar dashed line schematically reflects the apparent solubility of this amorphous form in a waterbased solution. The exact compositions of these phases are not known at this stage and are very hard to study, because of their metastability and the high temperatures.
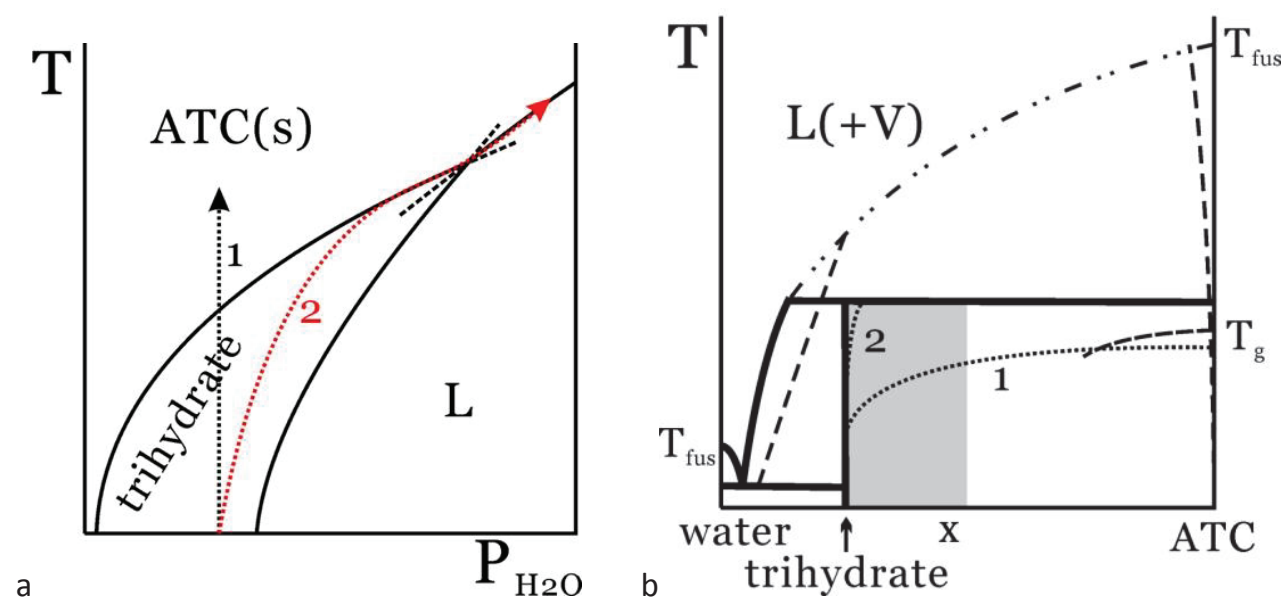

Figure 12. (a) Schematic ideal temperature - water-pressure phase diagram for the trihydrate of atorvastatin calcium with the crossing point of the three phase equilibria the incongruent fusion of the trihydrate at $155.8^{\circ} \mathrm{C}$. ATC(s) represents the hypothetical crystalline anhydrate, which has never been observed. In reality, full dehydration leads to a metastable mesophase or amorphous phase as described in the text. Other hydrates have been left out for clarity. The vertical dotted arrow (marked by 1 ) reflects a measurement in the TGA or in a DSC with pierced capsule -an open sytem. The curved dotted arrow (marked by 2 ) reflects a measurement in a closed DSC capsule -no exchange of matter-, in which water vapor cannot escape during the measurement. (b) Tentative binary phase diagram of water and atorvastatin calcium. $\mathrm{T}_{\text {fus }}$ is the respective melting temperature of pure water (left-hand side: $0^{\circ} \mathrm{C}$ ) and of pure atorvastatin calcium (right-hand side: unknown). Tg is the glass transition temperature of pure ATC $\left(144^{\circ} \mathrm{C}\right)$ with its extension into the binary phase diagram (horizontal dashed line). $\mathrm{L}$ is the liquid phase, which due to the high temperature must be accompanied by a vapor phase (V). The dotted line 1 marks the path of the TGA, SHG, X-ray and regular DSC measurements and the dotted line 2 marks the path of the trihydrate in the DSC measurement in a closed pan. The dashed upwards line is the amorphous phase of ATC with on the water-rich side of the phase diagram a dashed line representing the apparent 'solubility' of the amorphous phase (so-called demixing in the case of two liquid phases). The grey area represents a series of hydrate structures between the trihydrate and the monohydrate, that may exist simultaneously depending on the water-vapor pressure and the temperature. The dashed dotted line is the schematic liquidus of the hypothetical pure crystalline atorvastatin calcium, which cannot be determined experimentally by lack of an observed crystalline phase for anhydrous ATC. 


\section{CONCLUSIONS}

Sample identity and sample history cannot be ignored in particular if they concern hydrates or solvates, which contain components that can freely evaporate from or incorporate themselves in the crystal through air. Whether the system can lose a solvent molecule or not will affect the thermodynamic pathways followed by this system and hence its calorimetric and thermodynamic behavior will change as illustrated by the pathways 1 and 2 in Figure 12.

The so-called atorvastatin form I is in fact a trihydrate of atorvastatin calcium with a proper melting transition found at $155.8^{\circ} \mathrm{C}$ in the presence of saturated water vapor, whereas in an open environment the trihydrate ceases to exist around $95^{\circ} \mathrm{C}$, at which it is fully replaced by a dihydrate, which itself decomposes on heating while forming an anhydrous mesophase around $140^{\circ} \mathrm{C}$. Once the mesophase has turned into an isotropic liquid, the mesophase does not reappear on cooling. Moreover, the vitrified mesophase is most likely one of the two 'amorphous forms' observed for atorvastatin calcium.

The melting point of any, so-far hypothetical, anhydrous atorvastatin calcium crystalline form is not known, but may be found at temperatures in the order of $350{ }^{\circ} \mathrm{C}$, if a crystal form would ever be discovered. The reported glass transition temperature of $144^{\circ} \mathrm{C}$ is that of anhydrous atorvastatin calcium and it is therefore not related to the melting point of the trihydrate at $155.8^{\circ} \mathrm{C}$. Moreover, this melting point only exists under a saturated vapor pressure and in most regular DSC measurements peaks related to water loss are observed instead. The melting point at $155.8^{\circ} \mathrm{C}$ is also not related to the small peak observed in some regular DSC or TGA measurements at about $150^{\circ} \mathrm{C}$, which indicates the disappearance of the mesophase of anhydrate ATC.

It is important to verify observations obtained through DSC and/or TGA, because a peak reflecting a heat exchange is just that: a heat exchange. Whether such a heat exchange is the result of a phase transformation, a chemical reaction or an electrical current, will not be confirmed until it is observed with methods that are capable to provide a finger print of the system in real time, such as X-ray diffraction as a function of temperature. X-ray diffraction measurements carried out at room temperature after a DSC analysis may not reflect the identity of the phase at high temperature as during cooling and exposure to air phase transitions and water uptake may occur.

Finally, considering the absence of any observation of an anhydrous crystalline atorvastatin calcium in combination with a glass transition of $144{ }^{\circ} \mathrm{C}$, it can be concluded that amorphous atorvastation calcium in the absence of water can be kept at room temperature for a considerable amount of time without changing its amorphous state. This implies that anhydrous amorphous atorvastatin calcium could be used for formulations as such without the need of mixing it with excipients to keep it from crystallizing.

\section{ACKNOWLEDGEMENTS}

We thank F.X. Gendron of the SMS laboratory for his help with the SEM pictures and M. Schindler of the SMS laboratory for her help with the hot stage microscope. C. Tizaoui thanks the Tunisian Ministry for Higher Education and Scientific Research for a scholarship to spend three months in the SMS laboratory.

\section{FUNDING}

This work was supported by the MINECO, Project No. FIS2017-82625-P, and AGAUR, DGU Project No. 2017SGR-42 and by the SCAMPI project from the Normandie Region and the European Regional Development Fund (FEDER-FSE Normandie 2014-2020).

\section{DECLARATION OF INTEREST}




\section{REFERENCES}

Adhikari, B.R., Kim, D., Bae, J.H., Yeon, J., Roshan, K.C., Kang, S.K., Lee, H., 2016. New Category for Active Pharmaceutical Ingredients, a Low Molecular Weight Organogelator: Crystal Structure of Atorvastatin Calcium and Its Unusual Phase Transition Behavior during Dissolution. Cryst. Growth Des. 16, 7198-7204.

Antonio, S.G., Benini, F.R., Ferreira, F.F., Rosa, P.C.P., de Oliveira Paiva-Santos, C., 2012. Synchrotron X-ray powder diffraction data of atorvastatin. Powder Diffr. 23, 350-355.

Anwar, M., Warsi, M.H., Mallick, N., Akhter, S., Gahoi, S., Jain, G.K., Talegaonkar, S., Ahmad, F.J., Khar, R.K., 2011. Enhanced bioavailability of nano-sized chitosan-atorvastatin conjugate after oral administration to rats. Eur J Pharm Sci 44, 241-249.

Arunkumar, N., Deecaraman, M., Rani, C., Mohanraj, K.P., Kumar, K.V., 2009. Preparation and solid state characterization of atorvastatin nanosuspensions for enhanced solubility and dissolution. Int. J. PharmTech Res. 1, 1725-1730.

Asada, M.N., Nemoto, T., Mimura, H., 2016. Pharmaceutical Applications of Relaxation Filter-Selective Signal Excitation Methods for 19F Solid-State Nuclear Magnetic Resonance: Case Study With Atorvastatin in Dosage Formulation. J. Pharm. Sci. 105, 1233-1238.

Barrio, M., Maccaroni, E., Rietveld, I.B., Malpezzi, L., Masciocchi, N., Ceolin, R., Tamarit, J.L., 2012. Pressure-temperature state diagram for the phase relationships between benfluorex hydrochloride forms I and II: a case of enantiotropic behavior. J. Pharm. Sci. 101, 1073-1078. Bobe, K.R., Subrahmanya, C.R., Suresh, S., Gaikwad, D.T., Patil, M.D., Khade, T.S., Gavitre, B.B., Kulkarni, V.S., Gaikwad, U.T., 2011. Formulation and evaluation of solid dispersion of atorvastatin with various carriers. International Journal of Comprehensive Pharmacy 1, 1-6.

Briggs, C.A., Jennings, R.A., Wade, R.A., Harasawa, K., Ichikawa, S., Minohara, K., Nakagawa, S., 1997. Preparation of crystalline [R-(R*, $\left.\left.R^{*}\right)\right]-2-(4-f l u o r o p h e n y l)-\beta, \delta-$ dihydroxy-5-(1-methylethyl)-3-phenyl-4-[(phenylamino)carbonyl]-1H-pyrrole-1-heptanoic acid hemi calcium salt (atorvastatin). Warner-Lambert Company, USA . p. 49 pp.

Brus, J., Urbanova, M., Sedenkova, I., Brusova, H., 2011. New perspectives of 19F MAS NMR in the characterization of amorphous forms of atorvastatin in dosage formulations. Int. J. Pharm. 409, 62-74.

Byrn, S.R., Coates, D.A., Gushurst, K.S., Morrison, H.G., II, Park, A., Vlahova, P.I., Li, Z.J., Krzyzaniak, J.F., 2003. Crystalline forms of atorvastatin and its hydrates. Warner-Lambert Company, USA . p. 101 pp.

Campeta, A.M., Krzyzaniak, J.F., Leonard, J.A., 2005. Crystalline forms of atorvastatin free acid. Warner-Lambert Company LLC, USA . p. 28 pp.

Choudhary, A., Rana, A.C., Aggarwal, G., Kumar, V., Zakir, F., 2012. Development and characterization of an atorvastatin solid dispersion formulation using skimmed milk for improved oral bioavailability. Acta Pharmaceutica Sinica B 2, 421-428.

Christensen, N.P.A., Van Eerdenbrugh, B., Kwok, K., Taylor, L.S., Bond, A.D., Rades, T., Rantanen, J., Cornett, C., 2013. Rapid Insight into Heating-Induced Phase Transformations in the Solid State of the Calcium Salt of Atorvastatin Using Multivariate Data Analysis. Pharm. Res. 30, 826-835.

Clevers, S., Simon, F., Dupray, V., Coquerel, G., 2013. Temperature-resolved second harmonic generation to probe the structural purity of m-hydroxybenzoic acid. J. Therm. Anal. Calorim. 112, 1-7.

de Gennes, P.G., Prost, J., 1993. The physics of liquid crystals. Clarendon Press, Oxford, UK. 
Dong, W., Su, X., Xu, M., Hu, M., Sun, Y., Zhang, P., 2018. Preparation, characterization, and in vitro/vivo evaluation of polymer-assisting formulation of atorvastatin calcium based on solid dispersion technique. Asian J Pharm Sci 13, 546-554.

Galai, H., Lemsi, M., Louhaichi, M.R., Benrayana, M.C., Kalfat, R., 2015. Solid state characterization of atorvastatin in drug products. J. Chem. Pharm. Res. 7, 76-80.

Galwey, A.K., 2000. Macroscopic mechanisms and kinetics of the dehydration. Thermochim. Acta 355, 181-238.

Gutzow, I.S., Schmelzer, J.W.P., 2013. The vitreous state, 2nd ed. Springer, Heidelberg.

Holmes, S.T., Wang, W.D., Hou, G., Dybowski, C., Wang, W., Bai, S., 2019. A new NMR crystallographic approach to reveal the calcium local structure of atorvastatin calcium. Phys. Chem. Chem. Phys. 21, 6319-6326.

Jahan, R., Islam, M.S., Tanwir, A., Chowdhury, J.A., 2013. In vitro dissolution study of atorvastatin binary solid dispersion. J. Adv. Pharm. Technol. Res. 4, 18-24.

Jahangiri, A., Barzegar-Jalali, M., Garjani, A., Javadzadeh, Y., Hamishehkar, H., Afroozian, A., Adibkia, K., 2015. Pharmacological and histological examination of atorvastatin-PVP K30 solid dispersions. Powder Technol. 286, 538-545.

Kearney, A.S., Crawford, L.F., Mehta, S.C., Radebaugh, G.W., 1993. The interconversion kinetics, equilibrium, and solubilities of the lactone and hydroxyacid forms of the HMG-CoA reductase inhibitor, CI-981. Pharm. Res. 10, 1461-1465.

Kim, J.S., Kim, M.S., Park, H.J., Jin, S.J., Lee, S., Hwang, S.J., 2008a. Physicochemical properties and oral bioavailability of amorphous atorvastatin hemi-calcium using spraydrying and SAS process. Int. J. Pharm. 359, 211-219.

Kim, M.S., Jin, S.J., Kim, J.S., Park, H.J., Song, H.S., Neubert, R.H., Hwang, S.J., 2008b. Preparation, characterization and in vivo evaluation of amorphous atorvastatin calcium nanoparticles using supercritical antisolvent (SAS) process. Eur. J. Pharm. Biopharm. 69, 454-465.

Krzyzaniak, J.F., Laurence, G.M., Jr., Park, A., Quackenbush, K., Reynolds, M.L., Rose, P.R., Woods, T.A., 2006. Novel crystal forms of atorvastatin calcium. Warner-Lambert Company LLC, USA . p. 66 pp.

Krzyzaniak, J.F., Laurence, G.M., Park, A., Quackenbush, K.J., Reynolds, M.L., Rose, P.R., Woods, T.A., 2011. Forms of [r-(r*,r*)]-2-(4-fluorophenyl)- $\beta, \delta$-dihydroxy-5-(1-methylethyl)3-phenyl-4-[(phenylamino)carbonyl]-1h-pyrrole-1-heptanoicacid calcium salt (2:1). Pfizer, Inc., USA . p. No pp. given.

Kumar, N., Chaurasia, S., Patel, R.R., Khan, G., Kumar, V., Mishra, B., 2016. Atorvastatin calcium loaded PCL nanoparticles: development, optimization, in vitro and in vivo assessments. RSC Adv. 6, 16520-16532.

Kumar, N., Chaurasia, S., Patel, R.R., Khan, G., Kumar, V., Mishra, B., 2017. Atorvastatin calcium encapsulated eudragit nanoparticles with enhanced oral bioavailability, safety and efficacy profile. Pharm. Dev. Technol. 22, 156-167.

Lemsi, M., Galai, H., Louhaichi, M.R., Fessi, H., Kalfat, R., 2017. Amorphization of Atorvastatin Calcium by Mechanical Process: Characterization and Stabilization Within Polymeric Matrix. Journal of Pharmaceutical Innovation 12, 216-225.

Li, Z.B., Tao, W.H., Zhang, D., Wu, C.N., Song, B.B., Wang, S., Wang, T.Y., Hu, M.M., Liu, X.H., Wang, Y.J., Sun, Y.H., Sun, J., 2017. The studies of PLGA nanoparticles loading atorvastatin calcium for oral administration in vitro and in vivo. Asian J Pharm Sci 12, 285291.

Mahe, N., Nicolai, B., Barrio, M., Perrin, M.-A., Do, B., Tamarit, J.-L., Ceolin, R., Rietveld, I.B., 2013. Solid-State Properties and Dehydration Behavior of the Active Pharmaceutical Ingredient Potassium Guaiacol-4-sulfonate. Cryst. Growth Des. 13, 3028-3035. 
Mathew, J., Ganesh, S., 2002. Form V crystalline $\left[R\left(R^{*}, R^{*}\right)\right]-2-(4-f l u o r o p h e n y l)-\beta, \delta-$ dihydroxy-5-(1-methylethyl)-3-phenyl-4-[(phenylamino)carbonyl]-1H-pyrrole-1-heptanoic acid hemicalcium salt. (atorvastatin). Biocon India Limited, India . p. 25 pp.

Maurya, D., Belgamwar, V., Tekade, A., 2010. Microwave induced solubility enhancement of poorly water soluble atorvastatin calcium. J Pharm Pharmacol 62, 1599-1606.

Morale, F., Date, R.W., Guillon, D., Bruce, D.W., Finn, R.L., Wilson, C., Blake, A.J., Schröder, M., Donnio, B., 2003. Columnar Mesomorphism from Hemi-Disklike Metallomesogens Derived from 2,6-Bis[3',4',5'-tri(alkoxy)phenyliminomethyl]pyridines (L): Crystal and Molecular Structures of $\left[\mathrm{M}(\mathrm{L}) \mathrm{Cl}_{2}\right](\mathrm{M}=\mathrm{Mn}, \mathrm{Ni}, \mathrm{Zn})$. Chem. Eur. J. 9, 24842501.

Palanisamy, M., James, A., Khanam, J., 2016. Atorvastatin-cyclodextrin systems: Physiochemical and biopharmaceutical evaluation. J. Drug Delivery Sci. Technol. 31, 41-52.

Petit, S., Coquerel, G., 1996. Mechanism of several solid-solid transformations between dihydrated and anhydrous copper(II) 8-hydroxyquinolinates. Proposition for a unified model for the dehydration of molecular crystals. Chem. Mater. 8, 2247-2258.

Poupon, M., Barrier, N., Petit, S., Clevers, S., Dupray, V., 2015. Hydrothermal synthesis and dehydration of $\mathrm{CaTeO}_{3} \cdot\left(\mathrm{H}_{2} \mathrm{O}\right)$ : an original route to generate new $\mathrm{CaTeO}_{3}$ polymorphs. Inorg. Chem. 54, 5660-5670.

Pramanik, H.A.R., Das, G., Bhattacharjee, C.R., Paul, P.C., Mondal, P., Prasad, S.K., Rao, D.S.S., 2013. Tunable emissive lanthanidomesogen derived from a room-temperature liquidcrystalline Schiff-Base ligand. Chem. Eur. J. 19, 13151-13159.

Redondo, G.M., Berrocal, G.C., Zuniga, R.V., Arguedas, N.R., 2015. Identification of solid phase state of hemi-dihydrate atorvastatin in pharmaceutical raw materials. Scholars Acad. J. Pharm. 4, 102-107.

Rodde, M.S., Divase, G.T., Devkar, T.B., Tekade, A.R., 2014. Solubility and bioavailability enhancement of poorly aqueous soluble atorvastatin: in vitro, ex vivo, and in vivo studies. Biomed Res Int 2014, 463895.

Sarkar, R., Monjur-Al-Hossain, A.S.M., Sultana, R., Faroque, A.B.M., 2014. Improvement solubility of atorvastatin calcium using solid dispersion technique. Int. J. Pharm. Sci. Res. 5, 5405-5410.

Shete, G., Puri, V., Kumar, L., Bansal, A.K., 2010. Solid state characterization of commercial crystalline and amorphous atorvastatin calcium samples. AAPS PharmSciTech 11, 598-609.

Suri, S., Singh, J., Grewal, M.S., Raj, B., 2004. Atorvastatin calcium form VI or hydrates. Morepen Laboratories Limited, India . p. 34 pp.

Urbanova, M., Brus, J., Sedenkova, I., Policianova, O., Kobera, L., 2013. Characterization of solid polymer dispersions of active pharmaceutical ingredients by 19F MAS NMR and factor analysis. Spectrochim. Acta, Part A 100, 59-66.

Wang, W.D., Gao, X., Strohmeier, M., Wang, W., Bai, S., Dybowski, C., 2012. Solid-State NMR Studies of Form I of Atorvastatin Calcium. J. Phys. Chem. B 116, 3641-3649.

Zhang, H.X., Wang, J.X., Zhang, Z.B., Le, Y., Shen, Z.G., Chen, J.F., 2009. Micronization of atorvastatin calcium by antisolvent precipitation process. Int. J. Pharm. 374, 106-113. 
Click here to download Supplementary Material: Supplementary Materials_rev.docx 
CREDIT statement

Chaima Tizaoui

Haykel Galai

Maria Barrio

Simon Clevers

Nicolas Couvrat

Valérie Dupray

Gérard Coquerel

Josep-Lluis Tamarit

Ivo B. Rietveld

analysis, Supervision
Investigation, Validation, Visualization, Draft writing

Resources, Funding acquisition, Review-editing

Investigation, Visualization

Investigation, Review \& Editing

Investigation, Review \& Editing

Funding acquisition, Review \& Editing

Funding acquisition, Review \& Editing, Visualization

Funding acquisition, visualization, Review \& Editing

Conceptualization, Writing (Draft+Editing), Validation, Formal 